\title{
Assessment of Accelerated Partial Breast Irradiation as Monotherapy Following Breast Conserving Surgery in the Treatment of Favorable Risk Breast Cancer
}

\author{
Navesh K. Sharma1 ${ }^{*}$, Umer Ansari², Gregory Churchill³, Kruti Patel², Steven Feigenberg² \\ ${ }^{1}$ Division of Radiation Oncology, Penn State Hershey Cancer Institute, Hershey, PA, USA \\ ${ }^{2}$ Department of Radiation Oncology, University of Maryland School of Medicine, Baltimore, MD, USA \\ ${ }^{3}$ College of Osteopathic Medicine, University of New England, Biddeford, ME, USA \\ Email: *mohammed.balshy@yahoo.com
}

How to cite this paper: Sharma, N.K., Ansari, U., Churchill, G., Patel, K. and Feigenberg, S. (2018) Assessment of Accelerated Partial Breast Irradiation as Monotherapy Following Breast Conserving Surgery in the Treatment of Favorable Risk Breast Cancer. Advances in Breast Cancer Research, 7, 33-64.

https://doi.org/10.4236/abcr.2018.71004

Received: July 20, 2017

Accepted: January 23, 2018

Published: January 26, 2018

Copyright $\odot 2018$ by authors and Scientific Research Publishing Inc. This work is licensed under the Creative Commons Attribution International License (CC BY 4.0).

http://creativecommons.org/licenses/by/4.0/

\begin{abstract}
Accelerated partial breast irradiation (APBI) has been proposed as an alternative to whole breast radiotherapy in select patients undergoing post lumpectomy radiation therapy as part of a breast conserving approach. This comprehensive review attempts to assess the current literature and identify appropriate patients as well as supportive data.
\end{abstract}

\section{Keywords}

APBI, Breast Cancer, Breast Radiation, Partial Breast

\section{Introduction}

Preservation of normal appearance of the breast is an important objective in the treatment of breast cancer. Breast conserving surgery (BCS), either partial mastectomy or lumpectomy, followed by radiation therapy is now a well-established treatment of early stage breast cancer. The clinical outcome of breast conservation therapy (BCT) is equivalent or superior to either radical or modified radical mastectomy without adjuvant radiation therapy [1] [2] [3] [4]. The typical course of treatment consists of whole breast irradiation (WBI) delivered daily, 5 days a week, over 5 - 6 weeks and is often followed by a 1 - 2-week reduced field boost with electron beam, photons, or brachytherapy to the primary site. Local disease control and survival rates comparable to total mastectomy without radiation therapy are attained [5] [6]. 
The current standards for comparison of end-results in the local management of early stage breast cancer are mastectomy and BCS followed by WBI [1] [2] [3] [7]. Despite the efficacious alternative, a large proportion of women with breast cancer elect to undergo either a total mastectomy or BCS without the recommended adjuvant radiotherapy [8]-[13]. Patient preference may account for some cases, but many women appear to make this choice due to the logistical and personal difficulties associated with completing the standard $6-7$ weeks course of radiotherapy. As a consequence, local tumor control is suboptimal and the need for salvage mastectomy is higher than necessary. Although the predominant value of postoperative radiation therapy is local tumor control, some studies suggest that survival may also be enhanced [14].

Given the established efficacy of BCS, the current trend in radiation therapy for early stage breast cancer is to decrease the time in which the radiation is administered (hypofractionation), or decrease the volume treated (partial breast irradiation). Accelerated partial breast irradiation (APBI) encompasses both modifications to standard treatments, as both the volume and duration of treatment are reduced. The intent is to deliver radiation to those tissues that are at most risk of having residual cancer, while sparing uninvolved normal tissue. The entire course of radiation can be safely delivered in one week because the target volume is small, and only moderate doses of radiation are applied. This makes APBI a convenient alternative to WBI, allowing more women to complete adjuvant treatment, which has potential to increase breast preservation rates, and avoid the cost and morbidity of salvage mastectomy. This potential was recognized in the early 1990s, when APBI was introduced. The concept that breast cancer progresses from an index lesion in one part of the breast, and when detected early, only a part of the breast needs to be treated because this primary tumor site is, by far, the most common site of recurrence also supported development of this treatment technique [15]. Pioneering work in the modern era was first conducted at the Ochsner Medical Institutions in a phase II study utilizing multi-catheter volume interstitial brachytherapy, to compare with the standard use of external beam WBI. The study concluded that brachytherapy as the sole method of radiation therapy following segmental mastectomy had similar outcomes in regards to complication rates, cosmesis, and local control when compared to external beam radiation therapy [16].

A substantial body of literature supports the safety and efficacy of multi-catheter APBI [17]-[23]. Subsequently, a single entry site balloon catheter (MammoSite) was developed to simplify the applicator insertion process and mimic the multi-catheter dosimetry. Based upon favorable results in properly selected cases, brachytherapy APBI is a safe and effective treatment. These same APBI concepts were adapted to external beam techniques and pilot studies have shown promising results as well.

At the present time, there are two large scale phase III randomized trials underway designed to refine the indications and to compare the safety and efficacy 
of various APBI techniques to WBI. They are: 1) National Surgical Adjuvant Breast Project (NSABP) B-39/Radiation Therapy Oncology Group (RTOG)-0413 and 2) Group Europèen de Curiethèrapie-European Society of Therapeutic Radiation Oncology (GEC-ESTRO). The American Brachytherapy Society (ABS) and the American Society of Breast Surgeons (ASBS) have issued updated selection criteria for the general clinical application of brachytherapy APBI in the community [24] [25]. These criteria are not universally accepted. A consortium of German Oncology Societies consensus was APBI should be offered through a clinical trial [26]. The California Technical Assessment Forum (CTAF) has indicated that breast brachytherapy is the only form of radiation which does not meet their criteria for use in women with early breast cancer [27].

The prerequisites for the widespread adoption of APBI are:

1) Rationale is supported by patterns of local failure.

2) Reliable treatment methods are generally achievable.

3) Outcome data convincingly demonstrate tumor control equivalence to WBI.

4) Morbidity and cosmetic results are equivalent to WBI.

\section{Patterns of Disease Recurrence within the Breast}

The rationale for APBI comes from contemporary pathologic studies and patterns of failure following breast conservation treatment. For the majority of cases with small primary lesions, microscopic extension of disease beyond the index lesion is less than $1 \mathrm{~cm}$ [28] [29] [30] [31]; this falls within the range of the APBI techniques. Equally convincing are the clinical studies that show that most in-breast failures occurring in patients treated without radiation therapy are in the immediate vicinity of the lumpectomy cavity, and are referred to as "true recurrences" [6] [32] [33] [34]. Patterns of failure derived from 20 year follow up of the breast conservation studies from the European Institute of Oncology and the NSABP reveal that failure in the same breast remote from the site of lumpectomy (i.e. "elsewhere failures"), are infrequent $(<5 \%)$, despite the omission of postoperative WBI [5] [6] In other words, elsewhere failures are not reduced by WBI compared to no radiation therapy at all [35] [36] [37]. This generates a simple question: what is the role of WBI? For early breast cancers, the main effect of postoperative radiation is the prevention of local tumor recurrence at the site of the primary tumor [38]. These observations buttress the development and incorporation of APBI in the management of select breast cancer patients in order to minimize the likelihood of a local recurrence as well as radiation to healthy tissues.

\section{Treatment Methods}

The two requirements for success with APBI are accurate identification of the treatment target and achievement of dosimetry sufficient to control microscopic residual disease within the breast. Five approaches to partial breast irradiation 
have been developed with these goals in mind; four of them are APBI (multiple catheter, balloon catheter or similar derivative applicator, electronic brachytherapy, and external beam), and one of them is partial breast irradiation, but it is not "accelerated" (i.e. permanent seeds).

\section{Multiple Catheter Tube and Button (Multi-Catheter)}

There are two dose rate formats for breast brachytherapy: low dose rate (LDR) and high dose rate (HDR). The first experience with APBI in the United States was with multi-catheter low dose rate (LDR) inpatient brachytherapy [15] [39]. In this method, the prerequisite multi-catheter multi-plane implant is placed percutaneously into breast tissue in and around the resection site to create a 3-dimensional treatment volume that encompasses suspected residual microscopic disease. Local or regional anesthesia with sedation, or general anesthesia is needed for multi-catheter implants. LDR multi-catheter brachytherapy necessitates several inpatient hospital days to manage the indwelling radioactive sources. Continuous radiation safety precautions and restrictions are also required. Multi-catheter interstitial brachytherapy was used for many years as an LDR boost following whole breast radiotherapy [1]. It was adapted as a method of APBI when it was hypothesized that only part of the breast needed irradiation for small tumors. The major difference between the boost and definitive APBI is that APBI involves larger target volumes, shorter courses, and higher doses.

LDR brachytherapy has been largely replaced by HDR. HDR is the temporary insertion of a single, high activity radiation source by a computerized robotic delivery device. Unlike LDR, where there are continuous radiation safety concerns for medical personnel and family, with HDR, the radiation is confined to the patient. Because it is typically administered in a series of treatments over approximately 1 week, HDR can be conveniently performed in an outpatient setting [40].

Unlike the balloon catheter and related methods described below, the timing of the multi-catheter method is flexible because it does not depend upon a seroma cavity. The absence of the cavity, however, can make accurate targeting of the catheter placement less certain. Analysis of pretreatment images, surgical pathology, and image guidance of catheter placement is, therefore, paramount.

Multiple-catheter interstitial brachytherapy requires procedural skill and attention to target anatomy for optimal placement. The benefits of this modality are that it offers the most flexibility and highest level of dosimetry control due to the hundreds of potential source dwell positions created by the catheter matrix. The use of image guidance (CT, MRI and stereotactic mammography), template guides for catheter insertion, and 3D dosimetry have led to the opportunity for higher quality catheter placements [39] [41] [42] [43]. In addition the control over dwell positions and times (the duration the source remains at a given location along the catheter), offers an added dimension in dosimetry, resulting in one of the highest degrees of dose distribution control. Multicatheter APBI achieves high tumor control rates and has low complications rates. It is the APBI 
method with the longest follow-up [21] [22] [44].

\section{Balloon Catheter and Similar Multi-Channel Applicators}

The MammoSite $^{\mathrm{TM}}$ Radiation Therapy System (MammoSite ${ }^{\mathrm{TM}}$ ) developed by Proxima Therapeutics, Inc, is a single channel intracavitary balloon treatment device designed to simplify the brachytherapy procedure while maintaining the radiation dosimetry needed for APBI [45] [46] [47]. A deflated balloon catheter device is inserted into the resection site through the skin and then it is inflated to fill the lumpectomy cavity. The treatment target is $1 \mathrm{~cm}$ of compressed tissue adjacent to the surface of the balloon [45]. To achieve the proper dosimetry, the applicator must fit correctly into the surgical cavity without major air or fluid gaps. Furthermore, the balloon surface should be at least $7 \mathrm{~mm}$ beneath the surface of the skin. Correctly fitted applicators are believed to have dose distributions similar to those achieved with a fully encompassing multiple catheter implant [18] [45]. Once the device is appropriately placed, treatment is delivered with an HDR source which is inserted near the center of the balloon. Due to the relative ease of insertion, and the office-based site of service, balloon brachytherapy has become a common form of APBI.

Subsequent to the approval of the MammoSite ${ }^{\mathrm{TM}}$ a number of similar multi-channel alternative devices have been designed. The Contura device made by SenoRxhas multiple channels within the balloon [48]. There are also applicators available that lack the balloon component, but have multiple channels: Clear Path and Saviby (Cianna Medical [49] [50] [51]. These multi-channel devices with multiple source positions permit asymmetric distribution of radiation around the applicator. There are two specific advantages of these types of devices in comparison to single-lumen implants. First, applicators positioned too close to the skin (and perhaps the chest wall) that stress normal tissue tolerances can be dosimetrically adjusted to spare dose to these regions. Second, they can better accommodate irregular lumpectomy cavities or excision sites. Multi-channels applicators involve more complex computer planning and they are somewhat more bulky for patients to wear than the MammoSite. They require rotational orientation checks for proper treatment delivery.

The various brachytherapy applicator delivery systems, including multi-catheter, single channel balloon, and multi-channel devices, are all satisfactory approaches to breast brachytherapy. The radiation dosimetry, for example, is similar for balloon and interstitial methods [45] [52]. They are functional variants of interstitial brachytherapy when the sources are placed in optimal anatomic relationship to the surgical cavity, and if correct use of the inverse square principles of brachytherapy is made to deliver a high dose to the target, while maintaining relatively lower doses to surrounding normal tissue.

\section{External Beam}

APBI has been developed using external beam in various forms, including three-dimensional conformal radiation therapy (3D-CRT), intensity modulated radiation therapy (IMRT), Tomotherapy, and Proton Beam Therapy (PBT) [53]-[58]. The distribution of radiation typically involves a larger portion of the 
breast tissue than with breast brachytherapy, but the fractionation scheme is similar to HDR brachytherapy regimens. The appeal of EBRT for this particular treatment is the potential to make APBI accessible to more patients, since LDR and HDR techniques are not universally available. It is also a non-invasive alternative. These issues have provoked interest in examining EBRT as a means of delivering APBI.

In a multi-institution prospective study examining 3D-CRT dosed to $38.5 \mathrm{~Gy}$ 10 twice daily fractions, efficacy, cosmesis and toxicity at four years appear to be comparable to other APBI modalities [59] [60]. Subsequent single institution trials dosed to 49.95 Gy in 15 once daily fractions produced similar results at three years [61]. This technique certainly needs further exploration in a phase III trial as there are many factors to consider when comparing external beam with insertional devices. There is the potential to cause more normal tissue irradiation with EBRT because of the use of multiple beams and the inherent motion of the target with respiration [59] [62]. These concerns apply to IMRT-based APBI as well. A phase II prospective trial has reported correlation of volumes of treated chest wall and lung to post-treatment pain [62]. There are small single institution experiences with 3D-CRT and IMRT which have suggested unacceptable cosmetic outcomes and a high rate of late toxicity, mostly in the form of subcutaneous fibrosis [63] [64]. Results from more recent Phase II studies indicate improved normal tissue sparing offered by IMRT in comparison to 3D-CRT, which may lead to improved clinical outcomes in pain and cosmesis [65]. It is important to keep in mind uncertainties of dose, fractionation, dosimetry and outcomes when considering implementing EBRT for APBI until long-term data is available.

\section{Electronic Brachytherapy}

The newest form of APBI is electronic brachytherapy (XOFT Axxent ${ }^{\mathrm{im}}$, Xoft Inc., Sunnyvale, CA, USA). It follows the same basic principles as balloon brachytherapy, but uses a small kilo-voltage $\mathrm{X}$-ray source rather than a radionuclide. The electronic source of radiation has been miniaturized so that it can be inserted into the center of a breast brachytherapy balloon. As with HDR-based APBI techniques, electronic brachytherapy allows for significant dosimetric manipulation of dose through the use of various dwell positions. The major benefit of this modality over interstitial brachytherapy lies within the differences of shielding requirements. Use of HDR with Iridium-192 requires adequate shielding of treatment rooms to protect medical personnel and other patients in the surrounding areas. For facilities without such accommodations, electronic brachytherapy is a feasible alternative to offer to patients. There is multicenter observational data to suggest that satisfactory toxicity profile, cosmesis, device performance and local-regional recurrence rate can be achieved with this form of APBI [66].

\section{Permanent Seeds}

Permanent seed implantation is a form of LDR brachytherapy that has been 
used as a form of partial breast irradiation [67]. This technique is similar in concept to prostate brachytherapy, though the margins of the target are less well defined. This type of treatment offers convenience, as it can be completed in one day as an outpatient. Limitations of seed implantation include lack of precise control over seed distribution and increased radiation exposure to medical staff. Permanent seeds must also account for the heterogeneity of breast composition when calculating dosimetry. Factors such as increasing breast adipose proportion can decrease dose to the PTV while increasing dose to the skin [68].

\section{Intraoperative radiation therapy (IORT)}

Other approaches to APBI involve intraoperative radiation therapy (IORT), where radiation is delivered in the operating room immediately following the surgical excision. The target tissues are surgically exposed and normal tissues may be protected by shielding inserts. The disadvantages of such an approach are that only a single large dose (fraction) of radiotherapy is delivered to the surgical bed so the benefits of fractionation are not feasible and the final pathology report is not available for review of the extent of disease, margin analysis, and lymph node status. There are two forms of IORT. One is true external beam with electrons or photons delivered in the operating suite (Mobetron by Intraop Medical Corp) [69] [70] and the other is a form of electronic brachytherapy where a $50 \mathrm{kV}$ orthovoltage $\mathrm{X}$-ray source is inserted into direct contact with the operative cavity (Intrabeam by Carl Zeiss Meditec) [71] [72]. Finally, there is another approach to HDR where an external applicator is placed directly on the surface of the skin and treatment to the target is imaged guided daily with a mammogram. It is currently being used as a boost therapy with WBI, but has the potential for use as APBI [AccuBoost ${ }^{\mathrm{Tu}}$, Advanced Radiation Therapy, LLC, Billerica, MA, USA].

\subsection{Multiple Catheter Tube and Button}

Table 1 illustrates that properly standardized multi-catheter APBI achieves high tumor control rates and cosmetic outcomes comparable to 5 - 6 weeks of whole breast irradiation. The first long term outcome was reported from the Oschner clinic who reported 6 year follow up on 51 patients (26 HDR and 25 LDR) [16]. Local control in the breast was $98 \%$. This experience was used to develop RTOG 95-17 [22]. In that national study 99 patients were followed with a median follow up of 84 months. There were $66 \mathrm{HDR}$ ( $34 \mathrm{~Gy}$ in $10 \mathrm{BID}$ fractions of $3.4 \mathrm{~Gy}$ ) and $33 \mathrm{LDR}$ ( $45 \mathrm{~Gy}$ at $50 \mathrm{cGy} /$ hour) cases. Ipsilateral breast tumor control was achieved in $96 \%$. Only four (4\%) patients had true local recurrences and only one HDR patient failed within the treatment field.

The largest published multi-catheter APBI in the US comes from William Beaumont Hospital [44] [73] [74]. APBI was used on 199 patients from 1993-2001 in one of three different institutional review board approved protocols using either LDR (120 patients, $50 \mathrm{~Gy}$ at $52 \mathrm{cGy} / \mathrm{hr}$ ) or HDR (71 treated with $400 \mathrm{cGy} \times 8$ and 8 with $340 \mathrm{cGy} \times 10$ ). The median follow-up was 8 years. 
Table 1. APBI Multiple Catheter with selection criteria and quality assurance.

\begin{tabular}{|c|c|c|c|c|c|c|c|}
\hline \multirow[t]{2}{*}{ Author } & \multirow[t]{2}{*}{$\underline{\mathrm{f} / \mathrm{u}^{*} \text { (mo's) }}$} & \multirow[t]{2}{*}{ Treatment } & \multirow[t]{2}{*}{$\underline{\mathbf{n}}$} & \multicolumn{3}{|c|}{ Breast Failure (\%) } & \multirow{2}{*}{$\frac{\text { Cosmesis }}{\text { Good Excellent }}$} \\
\hline & & & & Total & True $^{* *}$ & Elsewhere & \\
\hline Fodor & 120 & WBI & & & & & \multirow{3}{*}{ Not stated } \\
\hline Arthur [22] & 84 & LDR 45 Gy & 33 & $12 \%$ & $10 \%$ & $3 \%$ & \\
\hline RTOG & & HDR 34Gy & 66 & $3 \%$ & $1.5 \%$ & $1.5 \%$ & \\
\hline King [16] & \multirow[t]{2}{*}{75} & LDR 45 Gy & 26 & \multirow[b]{2}{*}{$8 \%$} & \multirow[b]{2}{*}{$1 \%$} & \multirow[b]{2}{*}{$3 \%$} & \multirow[b]{2}{*}{$75 \%$} \\
\hline Ochsner Clinic & & HDR 32 Gy & 26 & & & & \\
\hline Vicini [44] [73] [74] & \multirow{2}{*}{96} & LDR $50 \mathrm{~Gy}$ & 120 & \multirow{2}{*}{$3 \%$} & \multirow{2}{*}{$1.5 \%$} & \multirow{2}{*}{$1.5 \%$} & \multirow{2}{*}{$99 \%$} \\
\hline William Beaumont & & HDR 32 - 34 Gy & 79 & & & & \\
\hline Ott. [20] & \multirow{2}{*}{32} & HDR 32 Gy, 4 Gy bid $\times 8$ & 99 & & \multirow{4}{*}{$<1 \%$} & & \multirow{4}{*}{$94 \%$} \\
\hline German-Austrian & & PDR 50 Gy 5days & 175 & $0.7 \%$ & & $<1 \%$ & \\
\hline Patel [19] & \multirow{2}{*}{49} & Low vs high risk disease & 183 low & $2.2 \%$ & & & \\
\hline Univ. Wisc ${ }^{\star * * * \star}$ & & HDR 32-34 Gy & 90 high & $4.4 \%$ & & Not available & \\
\hline $\begin{array}{l}\text { Arthur [40] } \\
\text { Virg. Commonwealth }\end{array}$ & 42 & $\begin{array}{l}\text { LDR } 45 \text { Gy } \\
\text { HDR } 34 \text { Gy }\end{array}$ & 13 & $0 \%$ & $0 \%$ & $0 \%$ & $80 \%$ \\
\hline $\begin{array}{c}\text { Kaufman [21] } \\
\text { Tufts/Brown Univ }\end{array}$ & 84 & HDR 34, Gy & 33 & $9 \%$ & $6 \%$ & $3 \%$ & $88 \%$ \\
\hline $\begin{array}{l}\text { Lawenda [82] } \\
\text { Mass General }\end{array}$ & 23 & LDR 50-60 Gy & 48 & $0 \%$ & $0 \%$ & $0 \%$ & $92 \%$ \\
\hline & 81 & HDR $30.3 \mathrm{~Gy}, 4.33 \times 7$ & & & & & \\
\hline Polgar C, et al. [77] & & HDR 36.4 Gy, 5.2 Gy × 7 & 45 & $6.7 \%$ & $0 \%$ & $6.7 \%$ & $84 \%$ \\
\hline NIO Hungary & & HDR $36.4,5.2 \mathrm{~Gy} \times 7$ & & & & & \\
\hline & 83 & Wide-vol electrons 50Gy & 80 & $10 \%$ & $3.8 \%$ & $6.3 \%$ & $68 \%$ \\
\hline Polgar et al. [77] [78] & & HDR $36.4,5.2 \mathrm{~Gy} \times 7$ & & & & & \\
\hline NIO Hungary & $67 \mathrm{ds}$ & Limited vo electrons $50 \mathrm{~Gy}$ & 128 & $4.7 \%$ & $2.3 \%$ & $2.3 \%$ & $77 \%$ \\
\hline Randomized & & Whole breast, $50 \mathrm{~Gy}$ & 130 & $3 \%$ & $1.5 \%$ & $1.5 \%$ & $69 \%$ \\
\hline & & WBI $50.0-50.4 \mathrm{~Gy} / 25-28 \mathrm{~F}$ & 673 & $0.92 \%$ & - & - & $63 \%$ \\
\hline $\begin{array}{c}\text { Strnad [79] } \\
\text { GEC-ESTRO }\end{array}$ & 60 & with $10 \mathrm{~Gy} / 5 \mathrm{~F}$ boost & & & & & \\
\hline & & APBI $32 \mathrm{~Gy} / 8 \mathrm{~F}$ or $30.3 \mathrm{~Gy} / 7 \mathrm{~F}$ & 675 & $1.44 \%$ & - & - & $81 \%$ \\
\hline $\begin{array}{l}\text { Yashar [81] } \\
\text { Strut Study }\end{array}$ & 59.5 & $\begin{array}{l}\text { Strut APBI } 34 \mathrm{~Gy} / 10 \mathrm{~F} \\
\text { (twice daily) }\end{array}$ & 250 & - & $2.3 \%$ & $3.6 \%$ & $85.9 \%$ \\
\hline
\end{tabular}

${ }^{\star}$ Median follow-up in months; ${ }^{*}$ Breast Failures divided into true (local at site primary) or elsewhere same breast; ${ }^{* * *} \mathrm{LDR}$ dose rates typically $50 \mathrm{c}$ Gy/hr;

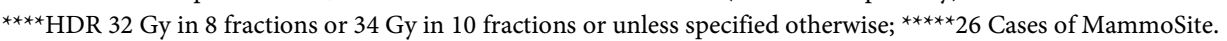

Six breast failures ( 5 breast only and 1 with axillary adenopathy) were observed giving a ipsilateral breast tumor recurrence (IBTR) rate $1.6 \%$ at 5 years and 3.8\% at 10 years. All six patients underwent successful salvage mastectomy. There were 3 additional supraclavicular regional lymph nodal failures resulting in a $1.6 \% 10$-year nodal failure rate. The 10 year survival rates were $94 \%$ disease-free survival (DFS), 96\% distant metastasis free survival (DMFS), and 95\% cause specific survival (CSS). Overall survival (OS) at 5 and 10 years was $87 \%$ and $73 \%$. 
Good to excellent cosmetic results achieved were 99\%. There were no serious complications; $4 \%$ had asymptomatic fat necrosis, $4 \%$ had grade II fibrosis, and $6 \%$ had grade I/II persistent edema. Long-term results with multi-catheter APBI demonstrated excellent long-term local and regional control rates and good to excellent cosmetic results.

A molecular clonality loss of heterozygosity assay was also performed on these patients to assess the relationship of local recurrences to the primary tumor [73] [75]. These genetic tests of tumor cells indicated that 5 of 6 (83\%) cases of local recurrences were clonally related to the original tumor (all successfully achieved local control with mastectomy). In contrast, only $1 / 7$ patients who developed distant metastases was found to be clonally related to the IBTR. With the low rate of local recurrences, and confirmation that the major source of those occurring in patients were of the primary tumor, this point further illustrates further the extent APBI control over the primary tumor.

In order to compare the rate of local control in patients with similar prognostic factors treated with WBI, $\mathrm{n}$ a matched pair analysis was performed [74]. The 199 APBI cases were matched from a reference group of 1388 patients treated with WBI at William Beaumont Hospital. Patients were matched for age, tumor size, histology, resection margin, the absence of extensive intraductal component, nodal status, tamoxifen use and follow-up. Between APBI and WBI no statistically significant differences were noted in the rates of local recurrence (both $1 \%$ ) regional failure (both $1 \%$ ) distant metastases (3\% vs. $5 \%$ ) disease free survival $(87 \%$ vs. $91 \%)$, overall survival $(87 \%$ vs. $93 \%)$, or cause specific survival (both 97\%). To supplement, related retrospective comparisons have concluded that APBI is an effective radiation treatment modality at least equivalent to whole breast external beam radiation therapy (EBRT) [41] [76].

The largest published results with multi-catheter interstitial brachytherapy APBI from outside the US are from the German-Austrian multi-center trial [20]. This phase II trial consisted of 274 patients between 2000 and 2005 with tumors $\leq 3 \mathrm{~cm}$, resection margins $\geq 2 \mathrm{~mm}$, $\mathrm{pN} 0$ or $\mathrm{pN} 1_{\text {mic }}$, no evidence of contralateral breast cancer or distant metastases, ER+ and $\geq 35$ years old. Sixty four percent (175/274) received pulsed-dose-rate (PDR) 49.8 Gy in 83 fractions of 0.6 Gy each hour and 36\% (99/274) received HDR 32 Gy in eight fractions. The median treatment time was 5 days and median follow-up was 32 months (range 8 - 68). IBTRs were observed in $2(0.7 \%)$ patients. The distant metastases free and overall survival rates were both $99 \%$. The cause specific survival was $100 \%$. Cosmetic results were excellent in 257/274 (94\%) by physician and 251/274 (92\%) by the patients. Morbidity was low; $4.7 \%$ fat necrosis, $0.45 \%$ grade 3 fibrosis, and $1.1 \%$ grade 3 telangiectasia.

Another significant APBI study (247/273 multicatheter brachytherapy; 26 MammoSite $^{\mathrm{Ts}}$ ) with 5 year results (median 49 months follow-up) used the NSABP/RTOG intergroup criteria to define "high and low risk groups" by having one or more of the following features: age $<50$ years, estrogen receptor negative, or one to three positive nodes without extra-capsular spread [19]. Impor- 
tantly, there were no significant differences in actuarial IBTR-free rates between the low and high risk groups (97.3\% and 93.6\%) and these findings are comparable to WBI. Three other studies listed in the table with 2 - 3 years follow up had no IBRT and a breast local control rate of $99 \%$.

Results from a prospective non-randomized study from the National Institute of Oncology Hungary demonstrated high local tumor control. IBTR was lower with APBI using HDR multi-catheter interstitial brachytherapy (6.7\%) than with electron beam WBI (10\%) after 81 months follow up. Cosmetic ratings for the HDR and WBI groups were good or excellent $84.4 \%$ and $68.3 \%$ respectively [77]. The axillary rate was $6.7 \%$ at a median follow-up of 57 months [78].

A randomized phase III trial from the same institution compared APBI $(n=$ $128)$ to WBI $(\mathrm{n}=130)$ [23]. Eligibility included negative surgical margins; unifocal tumor $\leq 20 \mathrm{~mm}$; cN0, pN0, or pN1mic and $\leq$ Grade 2. The APBI arm received either HDR $7 \times 5.2$ Gy bid 88/128 (68.8\%) or limited field electron beam to 50 Gy in 25 fractions $40 / 128$ (31.2\%) if the case was considered technically unsuitable for brachytherapy. WBI was median 50 Gy in 25 fractions. The median follow-up was 67 months. The 5-year IBTR were not significantly different; $4.7 \%$ for APBI and $3.4 \%$ for WB-EBRT ( $\mathrm{p}=0.50$ ). Overall, disease free, distant metastasis free, and cancer-specific survival rates at 5 years for APBI versus WBI were $95 \%$ vs. $92 \%, 88 \%$ vs. $90 \%, 93 \%$ vs. $93 \%$, and $98 \%$ vs. $96 \%$. The 5 -year probability for developing contralateral breast cancer after APBI was $7.1 \%$ and WB-EBRT was $2.4 \%$ (not significant at $p=0.12$ ). The rate of excellent to good cosmetic result was $78 \%$ in the APBI arm and $63 \%$ in the WBI arm $(p=0.009)$. Therefore, in this study, APBI did not increase the risk of IBTR, elsewhere failure in the breast, and there were no differences in OS, DFS, DMFS, or CSS. The cosmetic result for APBI was better than for WBI [78].

At this time, a five-year analysis of the randomized phase III trial, GEC-ESTRO has been published [79]. The study which aims to compare WBI with tumor-bed boost $(n=673)$ to APBI $(n=675)$ is further convincing of the efficacy and safety of APBI. The study recruited 1184 women with low-risk invasive carcinoma or low-risk DCIS (stages 0, I, IIa). Inclusion criteria were as follows: $\geq$ age $40, \leq 3 \mathrm{~cm}$ lesions without invasion or metastasis, and $2 \mathrm{~mm}$ resection margins. WBI utilized 50.0 - 50.4 Gy of photon beams at 25 - 28 fractions. The boost was $10 \mathrm{~Gy}$ at five fractions with electrons. APBI utilized $32 \mathrm{~Gy}$ at 8 fractions or $30.3 \mathrm{~Gy}$ at 7 fractions and had a safety margin of $20 \mathrm{~mm}$ with a coverage index $\geq 0.9$. Local recurrence occurred in five women of the WBI with boost arm and nine in the APBI arm (difference $0.52 \%, 95 \%$ CI -0.72 to $1.75 ; \mathrm{p}=0.42$ ). The primary endpoint was met, non-inferiority. Late skin side effects of a grade 2 - 3 were $5.66 \%$ for WBI and 3.23\% for APBI (difference $-2.43 \%$, 95\% CI -5.06 to $0.20 ; \mathrm{p}=0.0807)$. In addition, APBI showed greater disease free-mortality and overall mortality.

A 2016 review article analyzing 67 publications furthers the argument of non-inferiority in APBI v. WBI with regards to multi and single-entry catheters. 
Whilst only two studies have published inferiority of APBI (intraoperative trials ELIOT and TARGIT), many phase II and III trials continue to gather evidence contrary to this conclusion [80]. The highly anticipated trial, A Randomized Phase III Study of Conventional Whole Breast Irradiation (WBI) Versus Partial Breast Irradiation (PBI) for Women with Stage 0, I, or II Breast Cancer (NSABP B-39/RTOG 0413), will further elucidate the safety and efficacy of APBI in 2018.

A new advancement in brachytherapy is the use of strut-based applicators. Results of a 2016 retrospective study show that the first 250 participants have comparable local recurrence and cosmesis results to other major trials such as GEC-ESTRO. $34 \mathrm{~Gy} / 10 \mathrm{~F}$ (twice daily) were used and showed true recurrence/marginal miss at $2.3 \%$ and ipsilateral breast tumor recurrence at $3.6 \%$. Good to excellent cosmesis was reported in $85.9 \%$ of the participants [81].

\subsection{Balloon Catheter}

Table 2 presents the MammoSite ${ }^{\mathrm{Tm}}$ balloon catheter published results in cases with proper patient selection criteria and quality assurance. Since the balloon catheter was designed to achieve target coverage goals established with multi-catheter brachytherapy, it is believed that if properly applied and with good case selection the balloon catheter method will achieve comparable good long term outcomes as multi-catheter brachytherapy. It was approved for use by the FDA in May 2002 based on results from a phase I/II observational HDR trial (43 patients treated at 8 institutions) at 2 years reported little or no toxicity [46]. Morethan 50,000 patients have been treated with MammoSite ${ }^{\mathrm{rx}}$ devices since FDA approval was granted (data provided by Cytyc Surgical Products; http://www.mammosite.com/).

There are 5 observational balloon brachytherapy APBI trials available for review. The typical course of HDR brachytherapy consisted of $34 \mathrm{~Gy}$ in 10 fractions (3.4 given twice daily over 5 - 7 days).

Table 2. APBI MammoSite Balloon with selection criteria and quality assurance.

\begin{tabular}{cccccccc}
\hline Author & $\begin{array}{c}\mathbf{f} / \mathbf{u} \\
(\mathbf{m o} \mathbf{s})\end{array}$ & Treatment & $\mathbf{n}$ & & Breast Failure (\%) & Cosmesis \\
\hline & & & & Total & True** & Elsewhere & $\begin{array}{c}\text { Good } \\
\text { Excellent }\end{array}$ \\
\hline Keisch [46] Proxima & 21 & HDR 34Gy* & 43 & $0 \%$ & $0 \%$ & $0 \%$ & $88 \%$ \\
$\begin{array}{c}\text { Shah [88] ASBS } \\
\text { Benitez [17] }\end{array}$ & 63 & HDR 34Gy* & 1449 & 2.8 & $<1 \%$ & $2 \%$ & $91 \%$ \\
$\begin{array}{c}\text { William Beaumont } \\
\text { Cuttino [84] }\end{array}$ & 66 & HDR 34 Gy & 36 & $0 \%$ & $0 \%$ & $0 \%$ & $83 \%$ \\
$\begin{array}{c}\text { Multi-institutional } \\
\text { Belkacemi [86] } \\
\text { Lille II Univ. }\end{array}$ & 24 & HDR 34 Gy & 483 & $1 \%$ & $<1 \%$ & $<1 \%$ & $91 \%$ \\
$\begin{array}{c}\text { Chao [87] } \\
\text { William Beaumont }\end{array}$ & 22 & HDR 34 Gy & 25 & $0 \%$ & $0 \%$ & $0 \%$ & $84 \%$ \\
\hline
\end{tabular}

${ }^{*} \mathrm{HDR}$ is $34 \mathrm{G}$ in 10 fractions twice daily. 
The American Society of Breast Surgeons (ASBS) sponsored amulti-institution registry trial of MammoSite ${ }^{\mathrm{TM}}$ APBI. The final analysis was performed by Shah et al. on treatment performed on patients treated between May 2002 and June 2004 [18] [47] [83] [84]. With a total of 1449 cases, in a total 1440 patients $87 \%$ had invasive breast cancer and $13 \%$ had ductal carcinoma in situ (DCIS). Median follow up was 63 months. The 5-year actuarial IBTR rate was $3.8 \%$ (3.7\% for invasive and $4.1 \%$ for DCIS). In a multivariate analysis, invasive patients, estrogen receptor negativity ( 10.2 vs. $3.1 \%, \mathrm{OR}=3.6, \mathrm{p}=0.0003$ ) was associated with more frequent IBTRs. For DCIS patients only, age younger than 50 years $(19.0$ vs. $5.8 \%, \mathrm{OR}=3.8, \mathrm{p}=0.04)$ was associated with more frequent IBTRs. The percentage of breasts with good/excellent cosmetic results at 60 months was $91 \%$. Toxicity rates compared favorably to other APBI and WBI methods with infections, symptomatic seromas, and fat necrosis occurring at $10 \%, 13 \%$, and $2.5 \%$ respectively [85].

Amulti-institutional prospective MammoSite ${ }^{\mathrm{Tm}}$ series enrolled 70 patients $(\geq 45$ years old) with T1, N0 invasive ductal carcinoma with negative surgical margins during 2000-2001 [17]. Forty-three cases were selected for treatment and 27 cases were excluded on technical criteria ( 16 cases with cavity sizes $<3 \mathrm{~cm}$ or extensive intraductal component) and 11 cases of poor cavity conformance led to removal of the catheter without treatment. Seven patients were unavailable long term follow up ( 3 died or sent to hospice for unrelated illnesses, 2 had distant metastasis, 2 lost to follow up). There were no local or contralateral breast cancer failures in the 36 patients followed a median of 5.5 years. Cosmetic results were good to excellent in $83 \%$ in patients with 5-year follow up.

A large multi institution APBI balloon brachytherapy study enrolled 483 patients between 2000 and 2005. They received HDR 34Gy in 10 fractions over 5 days [81]. At a median follow-up of 24 months, there was $99 \%$ local control and $0.2 \%$ IBTR. Cosmesis was good to excellent/good in $91 \%$. Cause specific survival was $99.8 \%$.

A phase II study from Europe enrolled 43 patients 2003 to 2005 with T1N0 breast cancer [86]. The median age was 72 years. Twenty-five (58\%) patients were treated with high-dose rate brachytherapy using the MammoSite ${ }^{\mathrm{Tm}}$ applicator to deliver $34 \mathrm{~Gy}$ in 10 fractions. Publication of their early results (13 months median follow up) had no IBTRs and the rate of "good to excellent" cosmetic results was $84 \%$.

The William Beaumont Hospital treated 80 patients with MammoSite ${ }^{\mathrm{TM}}$ between 2000 and 2006 [87]. The 3-year IBTR was 2.9\%. There were no regional failures. Amolecular-based clonality assay indicated both recurrences were derived from the original primary tumors. Younger age was associated with IBTR. An $88.2 \%$ good to excellent cosmetic results were achieved at 36 months.

\subsection{External Beam Radiotherapy}

The most recent technique to be investigated as a method of APBI is external beam radiation therapy. Pilot studies have shown it is technically feasible and 
preliminary tumor control results were favorable [53] [89] [90]. Good dosimetry is a basic requirement for external beam APBI. Both 3D-CRT and IMRT techniques have been employed. Measures to optimize dosimetry include IMRT and cone-beam CT image guidance to improve precision and accuracy [91] [92]. In another study the dosimetry of 3 types of EBRT and multi-catheter interstitial APBI were compared $(n=13)$ [93]. It was concluded that PTV coverage was excellent with all techniques, but multi-catheter interstitial and prone tomotherapy resulted better normal tissue sparing than supine EBRT 3D-conformal or supine tomotherapy.

A randomized prospective phase III study in 1234 women with invasive breast cancer treated by lumpectomy with pathologically clear resection margins and negative axillary nodes were assigned to receive whole breast irradiation of 42.5 Gy in 16 fractions over 22 days ( $\operatorname{arm~A}$ ) or 50 Gy in 25 fractions over 35 days (arm B). The IBTR at 10 years was $6.2 \%$ in arm A and 6.7\% in arm B [94]. This regime with larger dose per fraction resulted in $70 \%$ of patients in arm $A$ and $71 \%$ in arm B reported good to excellent cosmetic results. There were no statistically significant differences in toxicity.

There are 4 observational studies of external beam APBI. The typical course of therapy consists of between $32-38.5$ Gy delivered twice daily over the course of one week. The results are summarized in Table 3.

A small 3D-CRT pilot study on 10 patients that delivered 25 - 30 Gy in 10 days achieved a 100\% local tumor control after 36 months of follow up [73]. A larger series consisting of 61 patients with T1N0, margin-negative breast tumors received 3D-CRT APBI between 2003 and 2005 [95]. The dose was 32 Gy in 8 fractions given twice daily. A combination of photons and electron beam was used in $85 \%$ of patients. Mean percent of the planning target volume (PTV) that received $100 \%$ dose was $93 \%+/-7 \%$. Dose in homogeneity exceeded $10 \%$ in 7 cases. Mean doses were $1.8 \mathrm{~Gy}$ to the ipsilateral lung and $0.8 \mathrm{~Gy}$ to the heart. The authors concluded that 3D-CRT APBI is feasible.

Another 3D-CRT APBI study of 91 patients used a target volume of the lumpectomy cavity plus $10-15 \mathrm{~mm}$ [96]. The prescribed dose was 34 or $38.5 \mathrm{~Gy}$ in 10 twice daily fractions. The median follow-up was 24 months. There were no local recurrences. Cosmetic results were rated as good/excellent in $91 \%$ at 2 years (n 21). Morbidity consisted of Grade I/II telangiectasia 9\%, fibrosis 18\%, fat necrosis $9 \%$ and transient grade III breast pain $3 \%$.

A more recent 3D-CRT APBI study of 98 patients used a planning target volume (PTV) by expanding on the lumpectomy cavity by $1.5-2 \mathrm{~cm}$. The total dose was 32 Gy using 4 Gy fractions given twice daily. The median follow up was 71 months. There were 5 IBTRs. All IBTRs were located more than $3 \mathrm{~cm}$ from the site of the primary tumor and had the same histology and receptor status as the initial tumors. Triple negative status was the only significant predictor of IBTR, with a hazard ratio of 15.4 (range, 2.6 - 92.9; $\mathrm{p}=0.0537$ ).

While 3D-CRT relies on physical wedges to reduce the dose delivered to adjacent healthy tissue, IMRT allows rapid re-blocking during patient treatment 
Table 3. APBI External Beam with patient selection criteria and quality assurance.

\begin{tabular}{|c|c|c|c|c|c|c|c|}
\hline \multirow[t]{2}{*}{ Author } & \multirow[t]{2}{*}{$\begin{array}{c}\mathrm{f} / \mathrm{u}^{*} \\
(\mathrm{mo} \text { 's) }\end{array}$} & \multirow[t]{2}{*}{ Treatment } & \multirow[t]{2}{*}{$\mathrm{n}$} & \multicolumn{3}{|c|}{ Breast Failure (\%) } & \multirow{2}{*}{$\begin{array}{c}\text { Cosmesis } \\
\text { Good } \\
\text { Excellent }\end{array}$} \\
\hline & & & & Total & True $^{* *}$ & Elsewhere & \\
\hline $\begin{array}{l}\text { Formenti S [89] } \\
\text { NYU }\end{array}$ & $>36$ & $\begin{array}{c}\text { Prone } \\
{ }^{\star} 25-30 \text { Gy } 5 \\
\text { fx } 10 \text { days, }\end{array}$ & 10 & $0 \%$ & $0 \%$ & $0 \%$ & $100 \%$ \\
\hline $\begin{array}{c}\text { Taghian [95] } \\
\text { Harvard }\end{array}$ & N.S. & *32 Gy 4 Gy bid × 8 & 61 & \multicolumn{4}{|c|}{ N.S. } \\
\hline $\begin{array}{c}\text { Vicini et al. [96] } \\
\text { William } \\
\text { Beaumont }\end{array}$ & 24 & $\begin{array}{c}* 34 \text { or } 38.5 \mathrm{~Gy} \\
\text { in } 10 \text { bid fx }\end{array}$ & 91 & $0 \%$ & $0 \%$ & $0 \%$ & $90 \%$ \\
\hline Vicini et al. [107] & \multirow[b]{2}{*}{10} & ${ }^{\star}$ Supine & \multirow[b]{2}{*}{31} & \multirow[b]{2}{*}{$0 \%$} & \multirow[b]{2}{*}{$0 \%$} & \multirow[b]{2}{*}{$0 \%$} & \multirow[b]{2}{*}{$100 \%$} \\
\hline $\begin{array}{l}\text { William } \\
\text { Beaumont }\end{array}$ & & $\begin{array}{c}* 38.5 \mathrm{~Gy}-3.85 \mathrm{~Gy} \\
\text { bid } \times 10\end{array}$ & & & & & \\
\hline Pashtan [108] & 71 & ${ }^{\star} 32 \mathrm{~Gy}-4 \mathrm{~Gy}$ bid fx 8 & 98 & $5 \%$ & $5 \%$ & $0 \%$ & N.S. \\
\hline $\begin{array}{l}\text { Lei et al. [65] } \\
\text { Institutional } \\
\text { Review Board }\end{array}$ & 60 & $* * 38.5 \mathrm{~Gy}-3.85$ bid fx & 136 & $<1 \%$ & $0 \%$ & $<1 \%$ & $90.5 \%$ \\
\hline $\begin{array}{c}\text { Bergom et al. } \\
\quad[103]\end{array}$ & 20 & **38.5 Gy -3.85 bid fx & 19 & $0 \%$ & $0 \%$ & $0 \%$ & $95 \%$ \\
\hline & & WBI 50 Gy & 130 & $4.6 \%$ & - & - & $63 \%$ \\
\hline Polgar [104] & 122 & PBI HDR $7 \times 5.2$ Gy & & & & & \\
\hline & & or EB $50 \mathrm{~Gy}$ & 128 & $5.5 \%$ & & & $81 \%$ \\
\hline Livi [105] & 60 & $\begin{array}{c}\text { WBI } 50 \mathrm{~Gy} / 25 \mathrm{~F} \text { with } \\
10 \mathrm{~Gy} \text { boosts/5 F }\end{array}$ & 260 & $1.4 \%$ & $1.9 \%$ & $0 \%$ & $99.2 \%$ \\
\hline U. Florence & & IMRT 30 Gy/5 F & 260 & $1.5 \%$ & $1.5 \%$ & $1.5 \%$ & $100 \%$ \\
\hline & & WBI $40 \mathrm{~Gy} / 15 \mathrm{~F}$ & 675 & $1.1 \%$ & - & - & - \\
\hline Coles [106] & 683 & WBI $36 \mathrm{~Gy} / 15 \mathrm{~F}$ and & 674 & $0.2 \%$ & - & - & - \\
\hline IMPORT LOW & & APBI 40 Gy/15 F & & & & & \\
\hline & & APBI $40 \mathrm{~Gy} / 15 \mathrm{~F}$ & 669 & $0.5 \%$ & - & - & - \\
\hline
\end{tabular}

N.S. $=$ Not Stated; $\mathrm{fx}=$ fractions; ${ }^{*}=3 \mathrm{D}-\mathrm{CRT} ;{ }^{* *}=\mathrm{IMRT}$.

which allows the provider to vary the size and intensity of treatment beams and deliver spatially non-uniform doses to allow a more homogenous dose distribution to the target site [65]. The higher degree of control has led to superior clinical outcomes using IMRT compared to 3D-CRT in tumors of various organs [97]-[102]. Although there are many advantages IMRT offers, there are relatively few groups that have investigated its use to deliver APBI. Two such studies are discussed.

A Phase II study gathered data on the efficacy of APBI using IMRT on 136 patients across 6 facilities, with stage $0 / 1$ breast cancer following breast-conserving therapy [65]. Patients received 38.5 Gy in 10 fractions delivered twice daily while supine. The clinical target volume was defined as $1 \mathrm{~cm}$ around the lumpectomy cavity. At four years there were promising efficacy results of IBTR (0.7\%), contralateral failures (0\%), OS (96.8\%), and Cancer Specific Survival (100\%). Physi- 
cian rated cosmesis was good to excellent in $90.5 \%$ of cases. While these results were comparable to other APBI methods, late toxicities comparing IMRT to other APBI techniques still requires further study.

Image guided IMRT was employed in a phase I/II trial of 20 patients to evaluate the feasibility of IMRT in the prone position [103]. Patients were given 38.5 Gy delivered in 10 fractions over 5 days, with a PTV of $2 \mathrm{~cm}$ around the lumpectomy cavity. With a median follow up of 19 months there were no recurrences and $95 \%$ of patients had good to excellent cosmesis. Dosimetric conformality and toxicity profiles were comparable to other APBI methods.

The Budapest randomized trial released 10-year results comparing APBI to WBI [104]. A total of 258 women were assigned to 50 Gy WBI ( $n=130), 5.2$ Gy/7 F multicatheter brachytherapy $(n=88)$, or 50 Gy electron beam irradiation. Inclusion criteria included unifocal tumor $(\leq 20 \mathrm{~mm})$ resected with wide negative margins and $<2 \mathrm{~mm}$ nodal micrometastases. Exclusion included previous malignancy, ductal or lobular carcinoma in situ, and extensive intraductal disease. APBI had 5.5\% local recurrence vs. $4.6 \%$ in the WBI arm ( $\mathrm{p}=0.77)$. Good to excellent cosmesis was seen in $63 \%$ of WBI versus $81 \%$ in APBI ( $p<$ 0.01). The results show a non-inferiority of APBI to WBI and also a better outcome in regards to cosmesis.

A five-year analysis of a randomized phase III trial out of the University of Florence shows that utilizing APBI with Intensity-modulated radiotherapy (IMRT) has comparable results to WBI with boost [105]. The study recruited 520 women, and divided them equally into the two arms $(n=260)$. Inclusion to the study required early breast cancer at $\geq 40$ years of age and a tumor diameter $\leq 2.5 \mathrm{~cm}$. Exclusion criteria included previously diagnosed solid tumors, multiple foci, cardiovascular disease, margins $<5 \mathrm{~mm}$, or extensive intraductal disease. WBI patients received a total of $50 \mathrm{~Gy}$ at 25 fractions with 10 Gy boosts at 5 fractions using direct external electron beam. IMRT utilized 30 Gy over five fractions in two weeks. The study showed that by intention to treat, local recurrence of breast cancer is not significantly higher in IMRT (1.5\%) when compared to WBI (1.4\%). A hazard ratio of 1.16 (95\% CI 0.23 - 5.75) is calculated along with a $\mathrm{p}=0.86$ when comparing APRI vs. WBI. Other significant findings included number of deaths in WBI $(n=8)$ v. APBI $(n=1)$ with $p=0.057$. Accounting for any grade of injury in each category, acute skins toxicity ( $\mathrm{p}=$ $0.0001)$, late skin toxicity $(\mathrm{p}=0.004)$, and physician-rated cosmesis $(\mathrm{p}=0.045)$ were superior in APBI. The authors make note that continued follow-up is warranted due to the low occurrence of adverse effects.

An abstract emerging from the United Kingdom further supports the evidence of non-inferiority when comparing APBI v. WBI. The IMPORT LOW trial is a phase III randomized trial comparing the two modalities in regards to local recurrence [106]. Inclusion criteria for the 2018 patients included $\geq 50$ years of age, $\leq 3 \mathrm{~cm}$ mass, and margins $\geq 2 \mathrm{~mm}$. Randomization occurred in a 1:1:1 ratio ( $\mathrm{n}=675 \mathrm{WBI}$ controls at $40 \mathrm{~Gy} / 15 \mathrm{~F}, \mathrm{n}=674$ to both WBI $36 \mathrm{~Gy} / 15 \mathrm{~F}$ and APBI 
$40 \mathrm{~Gy} / 15 \mathrm{~F}$, and lastly $\mathrm{n}=699$ at $40 \mathrm{~Gy} / 15 \mathrm{~F}$ of APBI. At the end of 5 years, local control was seen in the respective arms (1.1\% (95\% CI 0.5, 2.3), 0.2\% (95\% CI $0.02,1.2)$ and $0.5 \%(95 \%$ CI $0.2-1.4)$. The authors also report low rates of cosmetic injury in all arms without statistical data. A 10-year follow-up will be the next publication.

\subsection{Intra-Operative Radiotherapy (IORT)}

Intraoperative radiotherapy (IORT) in various forms has primarily been investigated mostly in Europe [109] [110] [111]. Two institutions are performing prospective randomized trials comparing IORT with WBI. At the University College of London (UCL) a low energy x-ray device, the Photon Radiosurgery System $\left(\mathrm{PRS}^{\mathrm{TM}}\right)$ developed by Photoelectron Corporation, is inserted into the lumpectomy cavity at the time of lumpectomy to deliver 21 Gy to a $2 \mathrm{~mm}$ depth [105]. After a median follow-up of 24 months on a pilot study there were no recurrences or major complications [111].

The European Institute of Oncology (EIO) EIO is performing targeted intraoperative trial (TARGIT) through 33 international centers in 11 countries [112]. It compares one fraction of $20 \mathrm{~Gy}$ with INTRABEAM ${ }^{\mathrm{mm}}$ (Photoelectron Corporation, Lexington, MA, USA) to a standard fractionated course of 50 Gy WBI using EBRT [113]. In November, 2013 5-year results for local recurrence were reported with an analysis of overall survival for 1721 patients treated with TARGIT and 1730 treated with EBRT [112]. There were no significant differences in risk of local recurrence or cause-specific mortality in patients treated with TARGIT vs. EBRT. There were significantly fewer grade 3 or 4 radiotherapy-related complications with TARGIT however.

The Instituto Europeo di Oncologia (IEO) has experience with electron intraoperative therapy (ELIOT) in over 3000 patients (>2000 as APBI). Local control on 1246 patients treated 1999 to 2005 with single fraction 21 Gy APBI was $97 \%$ with 2 - 7 years follow up [104]. They also contributed 1306 cases to the EIO randomized trial Tumors were $\leq 2.5 \mathrm{~cm}$, some node positive cases were included, age $\geq 48$. The cosmetic results were good in the majority of the patients both as evaluated by the patients themselves and by physicians. The frequency of local recurrences observed was similar to that of patients treated with conventional conservative surgery and WBI.

Two pilot IORT studies are underway in the United States [114] [115]. Memorial Sloan-Kettering Cancer Center has treated 50 women over 60 years of age with tumors T1 and clinically N0 [116]. A 20 Gy dose was administered to a depth of $1 \mathrm{~cm}$ immediately following wide local excision. A high rate of complications prompted dose reduction to $18 \mathrm{~Gy}$. Treatment volumes $\leq 47 \mathrm{~cm}^{3}$ and the low dose were associated with better cosmetic results. AIORT feasibility study is also underway at the University of North Carolina [115]. Selection criteria include age $\geq 55$, infiltrating ductal carcinoma, $\mathrm{T} \leq 3 \mathrm{~cm}$. A dose of $15 \mathrm{~Gy}$ is delivered with a magnetron linear accelerator (Intraop Corp, Santa Clara, CA, USA). 
Treatment will be given prior to lumpectomy through a standard partial mastectomy incision to the $90 \%$ isodose line using $1 \mathrm{~cm}$. anteroposterior and $2 \mathrm{~cm}$. lateral margins (Table 4).

\subsection{Proton Beam}

Preliminary experience with proton beam APBI in 20 patients has been reported [56]. There were no local failures within the first 12 months of follow up but acute skin reactions prompted the authors to modify the technique. Good-to-excellent cosmetic results were noted after 12 months in all cases.

Proton beam therapy (PBT) has also been shown to reduce the expression of Cyclooxygenase-2(COX-2) and Matrix Metalloproteinase-9 (MMP-9) which have been shown to increase cell migration and proliferation in various cancers including colon, lung and breast cancer [117]. The study revealed that external PBT prevented the phosphorylation of Protein Kinase B (PKB) a regulator of COX-2 and MMP-9 and thus prevented their expression.

Intensity modulated proton beam therapy (IMPT) for APBI is delivered via a scanning proton pencil beam, which paints the treatment target spot-by-spot, using scanning magnets to control lateral spot location while varying initial proton energy to control spot depth [118]. IMPT significantly was show to significantly reduce the dose to normal tissue compared with 3 DCRT [119]. While studies have indicated that PBT, as well as IMPT using scanning beams produces superior dose distribution for multiple disease sites, IMPT is sensitive to delivery uncertainties [120] [121] [122]. The large variation in dose from these uncertainties can result in under-dosing of target tissues, or overdosing normal tissues.

A phase I trial examined relative toxicities in patients treated with APBI comparing 3D-CRT photon based techniques and PBT [123]. 98 patients with stage I breast cancer were given 32 Gy in 8 fractions twice daily, of which 19 were

Table 4. APBI Intraoperative with patient selection criteria and quality assurance.

\begin{tabular}{|c|c|c|c|c|c|c|c|}
\hline \multirow[t]{2}{*}{ Author } & \multirow[t]{2}{*}{$\begin{array}{l}\mathrm{f} / \mathrm{u}^{*} \\
(\mathrm{mo} \text { 's) }\end{array}$} & \multirow[t]{2}{*}{ Treatment } & \multirow[t]{2}{*}{$\mathrm{n}$} & \multicolumn{3}{|c|}{ Breast Failure (\%) } & \multirow{2}{*}{$\begin{array}{c}\text { Cosmesis } \\
\text { Good } \\
\text { Excellent }\end{array}$} \\
\hline & & & & Total & True ${ }^{* *}$ & Elsewhere & \\
\hline Vaidya [111] & & $\mathrm{kV}$ photons & & & & & \\
\hline $\begin{array}{l}\text { U College of } \\
\text { London }\end{array}$ & 24 & $\begin{array}{c}21 \mathrm{~Gy}(0.2 \mathrm{~cm} \\
\text { depth })\end{array}$ & 25 & $0 \%$ & $0 \%$ & $0 \%$ & N.R. \\
\hline $\begin{array}{c}\text { Veronesi [110] } \\
\text { European Inst Onc }\end{array}$ & 19 & $\begin{array}{c}\text { Electrons } \\
17-21 \mathrm{~Gy} \text {, one } \mathrm{fx}\end{array}$ & 237 & $1.4 \%$ & $0 \%$ & $1.4 \%$ & N.R. \\
\hline $\begin{array}{l}\text { Instituto Europeo } \\
\text { di Oncologia [110] } \\
\text { (ELIOT) }\end{array}$ & 21 & $\begin{array}{c}\text { Electrons } \\
20 \text { Gy one } \mathrm{fx}\end{array}$ & 1246 & 3.3 & 2.4 & 0.9 & N.R. \\
\hline $\begin{array}{c}\text { Instituto Europeo } \\
\text { di Oncologia [111] } \\
\text { [112] [116] } \\
\text { (TARGIT) }\end{array}$ & 29 & $\begin{array}{l}50 \mathrm{kV} \text { x-rays } \\
20 \mathrm{~Gy} \text { one } \mathrm{fx}\end{array}$ & 1721 & 3.3 & N.R & N.R. & N.R. \\
\hline
\end{tabular}


treated using PBT and 79 were treated with 3D-CRT photons. At a median follow up of 83 months local recurrences were similar between the groups (6\% and $4 \%$ in PBT and photon groups respectively). Physician rating of overall cosmesis was good or excellent for $62 \%$ of PBT patients, compared to $94 \%$ for photons patients $(\mathrm{p}=0.03)$. PBT also caused higher rates of long-term telangiectasia, skin toxicities, and skin color changes. More advanced techniques for PBT may yet be required for it to achieve cosmetic and toxicity profiles comparable with other techniques. Proton beam therapy is also more costly than conventional treatment and potential benefits must be weighed with the consideration of the associated costs to the health-care system [124].

\subsection{Permanent Seeds}

The first report of permanent breast seed implants (PBSI) using Pd-103 seeds came from Sunnybrook and Women's College Health Sciences Centre. There were 16 patients with early-stage breast cancer referred to the hospital for adjuvant breast irradiation after breast-conserving surgery that underwent PBSI [125]. An average of 70 seeds were used (range, 44 - 90 seeds), and planning target volume (PTV) receiving at least $100 \%$ of the prescribed dose (V100) was $95.0 \%$ on average. The procedure was well tolerated in regards to pain, and acute skin toxicity was minimal during the 2 months after the implantation. All patients had complete healing at 2-month follow-up.

A subsequent Phase I/II trial performed included 67 patients with infiltrating ductal carcinoma treated with a Pd-103 permanent breast seed implant as adjuvant radiation therapy after breast-conserving surgery [126]. The trial aimed for post-implant dosimetry coverage similar to prostate brachytherapy, with the PTV receiving a V100 of greater than $90 \%$. A median of 71 seeds were implanted per patient (range, 33 - 102 seeds). The first half of patients study received a mean post-implant V100 of $82 \%$ compared with $89 \%$ for the second half of the patients. After a median follow-up of 32 months, no patient developed a breast recurrence. Overall, treatment with PBSI was well tolerated, with less than 5\% of patients experiencing significant pain during the procedure and without any immediate perioperative complications [67]. The prescription dose of $90 \mathrm{~Gy}$ to the target volume was based on a time-dose fractionation schedule equivalent to $50 \mathrm{~Gy}$ in 25 fractions of external beam radiation [127]. However, the ideal prescription dose is currently unknown.

\section{APBI Results in Cases without Strict Selection Criteria or Quality Assurance}

Table 5 shows results of studies without clear or limited selection criteria and poor quality assurance measures. Unlike the results in patients with well-defined selection criteria and quality assurance measures which compare favorably to whole breast radiotherapy, those without selection criteria and quality assurances are unsatisfactory. Proper case selection and quality control of the specific technique must be applied if good outcomes are to be expected. 
Table 5. APBI without patient selection criteria and quality assurance.

\begin{tabular}{cccccccc}
\hline Author & $\begin{array}{c}\mathbf{f} / \mathbf{u}^{*} \\
(\mathbf{m o})\end{array}$ & Treatment & $\mathbf{n}$ & Breast Failure (\%) & Cosmesis \\
\hline & & & Total & True* & Elsewhere & $\begin{array}{c}\text { Good } \\
\text { Excellent }\end{array}$ \\
\hline $\begin{array}{c}\text { Fentiman [128] } \\
\text { Guy's Hospital }\end{array}$ & 72 & $\begin{array}{c}\text { Multi-cath, LDR } \\
55 \text { Gy (40c Gy/hour) } \\
\text { Limited field } \\
\text { electron }\end{array}$ & 27 & 37 & $83 \%$ & No & No \\
$\begin{array}{c}\text { Magee [129] } \\
\text { Christie Hospital }\end{array}$ & 96 & 25 & na & No & No \\
$\begin{array}{c}\text { Perera [130] } \\
\text { London Reg Ca } \\
\text { Centre Canada }\end{array}$ & 91 & $\begin{array}{c}\text { Multicath HDR } \times 8 \mathrm{fx} \\
37.2 \mathrm{~Gy} \times 10 \mathrm{fx}\end{array}$ & 39 & 15.4 & $90 \%$ & \pm Yes & No \\
\hline
\end{tabular}

\section{Patient Selection Criteria}

Patient selection criteria for APBI have been defined by the American Brachytherapy Society and the American Society of Breast Surgeons as shown in Table 6. The intent of the criteria is to identify the subgroup of women that have a limited risk of elsewhere failures and therefore are the best candidates for this treatment approach. Patients with infiltrating lobular carcinoma and those patients with 1 - 3 positive nodes have previously been excluded from general application of APBI techniques. Pathologic findings such as multi-centric tumor and extensive intraductal carcinoma should be viewed in the context of the other clinical features.

The use of radiation therapy of any kind requires special consideration for patients with autoimmune disorders such a systemic lupus erythematosis or scleroderma. The indications for APBI may at some point be expanded if the results of clinical trials such as NSABP B-39/RTOG 0413 show that they can be as safely and effectively treated with APBI as with WBI.

The American Society for Radiation Oncology (ASTRO) has defined three subsets of patients when considering APBI as treatment; "suitable", "cautionary", and "unsuitable" groups. All patients being considered for APBI should be candidates for BCT with no prior radiotherapy, history of collagen vascular diseases, and should not be pregnant. Patients should be committed to long term follow-up to check for recurrences, other primary cancers, and toxicity from treatment [133]. A Surveillance Epidemiology and End Results (SEER) analysis calculated that 44,797 (41.2\%) women treated for breast cancer between 2010-2012 showed eligibility for APBI according to ASTRO guidelines [134] (Table 7).

\section{Randomized Prospective Clinical Trials}

There are three approaches to APBI in general use; multi-catheter, balloon catheter and similar devices, and 3D-CRT. Outcome data indicates that multi-catheter brachytherapy is comparable to WBI for properly selected cases. When correctly administered balloon brachytherapy offers similarly satisfactory dosimetry. Although there is less follow up studies with proper case selection 
Table 6. Selection criteria for accelerated partial breast irradiation.

\begin{tabular}{|c|c|c|}
\hline & $\frac{\text { American Brachytherapy Society }}{[131]}$ & $\frac{\text { American Society of Breast Surgeons }}{[132]}$ \\
\hline Age & $\geq 50$ years & $\geq 45$ years \\
\hline Histology & Invasive Ductal Carcinoma & $\begin{array}{l}\text { Invasive Ductal Carcinoma } \\
\text { Ductal Carcinoma In Situ }\end{array}$ \\
\hline Stage/Size & $\mathrm{T} 1$ and $\mathrm{T} 2 \leq 3 \mathrm{~cm}$ & $\mathrm{~T} 1$ or $\mathrm{T} 2 \leq 3 \mathrm{~cm}$ \\
\hline Margin Status & $\begin{array}{c}\text { Negative } \\
\text { No tumor at inked margin }\end{array}$ & $\begin{array}{c}\text { Negative } \\
\text { at least } 2 \mathrm{~mm} \text { in all directions }\end{array}$ \\
\hline $\begin{array}{c}\text { Lymph Nodal } \\
\text { Status }\end{array}$ & $\begin{array}{c}\text { Negative (N0) } \\
\text { Axillary dissection orsentinel lymph } \\
\text { node evaluation required }\end{array}$ & $\begin{array}{c}\text { Negative (N0) } \\
\text { Axillary dissection orsentinel lymph } \\
\text { node evaluation required }\end{array}$ \\
\hline Distant Metastases & None & None \\
\hline
\end{tabular}

Table 7. ASTRO selection criteria for accelerated partial breast irradiation.

\begin{tabular}{|c|c|c|c|}
\hline Patient factors & Suitable & Cautionary & Unsuitable \\
\hline Age & $\geq 60 y$ & $50-59 y$ & $<50 \mathrm{y}$ \\
\hline$B R C A 1 / 2$ mutation & Not present & & Present \\
\hline \multicolumn{4}{|l|}{ Pathologic factors } \\
\hline Tumor size & $\leq 2 \mathrm{~cm}^{*}$ & $2.1-3.0 \mathrm{~cm}$ & $>3 \mathrm{~cm}$ \\
\hline T stage & $\mathrm{T} 1$ & $\mathrm{~T} 0$ or $\mathrm{T} 2$ & T3-4 \\
\hline Margins & Negative by at least $2 \mathrm{~mm}$ & Close $(<2 \mathrm{~mm})$ & Positive \\
\hline Grade & Any & & \\
\hline LVSI & $\mathrm{No}^{* *}$ & Limited/focal & Extensive \\
\hline ER status & Positive & Negative & \\
\hline Multicentricity & Unicentric only & & Present \\
\hline Multifocality & $\begin{array}{l}\text { Clinically unifocal with } \\
\text { total size } \leq 2.0 \mathrm{~cm} \neq \ddagger\end{array}$ & $\begin{array}{l}\text { Clinically unifocal with } \\
\text { total size } 2.1-3.0 \mathrm{~cm} \neq \ddagger\end{array}$ & $\begin{array}{c}\text { If microscopically } \\
\text { multifocal }>3 \mathrm{~cm} \text { in } \\
\text { total size or if clinically } \\
\text { multifocal }\end{array}$ \\
\hline Histology & $\begin{array}{l}\text { Invasive ductal or other } \\
\text { favorable subtypes }\end{array}$ & Invasive lobular & \\
\hline Pure DCIS & Not allowed & $\leq 3 \mathrm{~cm}$ & If $>3 \mathrm{~cm}$ in size \\
\hline EIC & Not allowed & $\leq 3 \mathrm{~cm}$ & If $>3 \mathrm{~cm}$ in size \\
\hline Associated LCIS & Allowed & & \\
\hline \multicolumn{4}{|l|}{ Nodal factors } \\
\hline $\mathrm{N}$ stage & $\mathrm{pN} 0\left(\mathrm{i}^{-}, \mathrm{i}^{+}\right)$ & & $\mathrm{pN} 1, \mathrm{pN} 2, \mathrm{pN} 3$ \\
\hline Nodal Surgery & SN Bx or ALNDII II & & None Performed \\
\hline \multicolumn{4}{|l|}{ Treatment Factors } \\
\hline $\begin{array}{c}\text { Neoadjuvant } \\
\text { Therapy }\end{array}$ & Not allowed & & If used \\
\hline
\end{tabular}

${ }^{*}$ Size of the invasive tumor component as defined by the American Joint Committee on Cancer [135]; ${ }^{*}$ The finding of possible or equivocal LSVI should be disregarded; 抹 Microscopic multifocality allowed, provided the lesion is clinically unifocal and the total lesion size (including foci of multifocality and intervening normal breast parenchyma) falls within the allotted range. 
and quality measures demonstrate outcomes similar to multi-catheter. APBI with 3D-CRT also has a favorable study profile and patterns of care suggest it is valid though less tested alternative. Several randomized clinical trials are in progress. The NSABP B-39/RTOG 0413) prospective randomized trial results are much anticipated since it compares APBI directly to WBI. Unfortunately, the trial does not randomize to various forms of APBI and there appears to be a selection bias toward 3D-CRT (approximately $70 \%$ of the APBI cases were so treated). The other important aspect of the trial is determination of the indications for APBI. The GEC-ESTRO APBI trial opened in 2004 also compares interstitial APBI to WBI in low risk invasive cancer and ductal carcinoma in situ. Since analysis must await full accrual the results of both these studies will not be available for some time to come. The long term results of the Hungarian which finished accruing in 2004 demonstrates that multi-catheter APBI is safe and effective treatment for properly selected cases [23]. IORT has accumulated considerable prospective supportive data. The result of the randomized IORT versus WBI trial is pending.

\section{Socioeconomic and Practical Considerations}

There are many reasons to have APBI available as a treatment option.

1) Supporting Data: There is sufficient outcome and safety data to support applications in early breast cancer.

2) More convenient: A short course of radiation is more convenient than a long one.

3) Improved access: According to the SEER database, upwards of $40 \%$ of lumpectomy patients do not receive adjuvant radiation therapy. In effect, a large proportion of women with breast cancer lack access to standard radiation therapy. Under utilization of radiation therapy leads to higher local failure rates, more salvage mastectomies, and it may in some cases result in decreased survival. APBI with its short course makes it possible for more women undergo the recommended adjuvant radiation therapy. Offering APBI would improve health outcomes for the population of women with breast cancer.

4) Improved breast conservation rates: APBI would improve the breast conservation rates. It has been shown that the percentage of women getting mastectomies as initial treatment is proportional to the distance from a radiation therapy center. Although it may not be the only factor, the obvious conclusion is that many women choose mastectomy because they are unable to access the facility or afford the transportation, lodging or time away from home or work. APBI would allow many of these women to select breast preservation.

5) Potentially less toxic: Whole breast radiation may be more toxic to surrounding tissues that APBI particularly in women with certain underlying cardiopulmonary or systemic illnesses due to less tissue irradiated with APBI.

Approximately two years ago, the NSABP B39/RTOG 0143 clinical trial of partial breast irradiation changed eligibility criteria to exclude "low risk" patients by limiting enrollment to women under the age of 50 or those who were 
found to be ER negative and/or node positive so that patients with more aggressive disease could be studied. Similarly, the ASBS registry is currently closed to accrual. We support entry of patients who do not meet the ABS or ASBS selection criteria on treatment protocols but many patients are no longer eligible and many patients cannot or do not want to be part of a study. Patients who meet the selection criteria have access to APBI.

A detailed decision analysis for partial breast irradiation versus whole breast radiation therapy for early stage breast cancer was performed by the Institute for Technology Assessment at the Massachusetts General Hospital and Harvard University [136]. A comparison was performed of the quality-adjusted life expectancy between women treated with partial breast radiation versus whole breast radiation therapy for estrogen receptor positive early stage breast cancer. This analysis showed that partial breast radiation was superior to conventional whole breast radiation therapy in quality-adjusted life expectancy and that partial breast irradiation was the preferred treatment modality. At a minimum, patients should have reasonable access to such treatment.

\section{Conclusions and Summary Recommendations}

APBI has an established role in early breast cancer. Proper case selection and quality control measures of the treatment process are key ingredients for a successful outcome. Randomized clinical trials will clarify selection and exclusion criteria.

The following guidelines are recommended:

1) Established selection criteria should be used;

2) The target volume should include the $1-2 \mathrm{~cm}$ margin of tissue surrounding the lumpectomy cavity;

3) One of the accepted techniques familiar to the practitioner should be employed;

4) The target volume and normal tissue dosimetry should be consistent with accepted standard parameter, such as using with RTOG 95-17 or NSABP B-39/RTOG 0413;

5) The applicator to target relationships should be verified by imaging prior to treatment delivery.

\section{References}

[1] De Vita, L.T. and Rosenberg, S. (2008) Principles and Practice of Oncology. 8th Edition, Philadelphia, PA.

[2] P. Leibel S. (2004) Textbook of Radiation Oncology. Saunders, Philadelphia, PA.

[3] Perez, C., et al. (2003) Principles and Practice of Radiation Oncology. Philadelphia, PA.

[4] (1991) NIH Consensus Development Conference Statement on the Treatment of Early-Stage Breast Cancer. Oncology (Williston Park), 5, 120-124.

[5] Fisher, B., et al. (2002) Twenty-Year Follow-Up of a Randomized Trial Comparing Total Mastectomy, Lumpectomy, and Lumpectomy plus Irradiation for the Treat- 
ment of Invasive Breast Cancer. The New England Journal of Medicine, 347, 1233-1241. https://doi.org/10.1056/NEJMoa022152

[6] Veronesi, U., et al. (2002) Twenty-Year Follow-Up of a Randomized Study Comparing Breast-Conserving Surgery with Radical Mastectomy for Early Breast Cancer. The New England Journal of Medicine, 347, 1227-1232. https://doi.org/10.1056/NEJMoa020989

[7] Silverstein, M.J., et al. (2005) Image-Detected Breast Cancer: State of the Art Diagnosis and Treatment. Journal of the American College of Surgeons, 201, 586-597. https://doi.org/10.1016/j.jamcollsurg.2005.05.032

[8] Athas, W.F., et al. (2000) Travel Distance to Radiation Therapy and Receipt of Radiotherapy Following Breast-Conserving Surgery. Journal of the National Cancer Institute, 92, 269-271. https://doi.org/10.1093/jnci/92.3.269

[9] Hebert-Croteau, N., et al. (1999) Variations in the Treatment of Early-Stage Breast Cancer in Quebec between 1988 and 1994. CMAJ, 161, 951-955.

[10] Du, X.F.J., Freeman, D.H., et al. (1999) Temporal and Regional Variation in the Use of Breast-Conserving Surgery and Radiotherapy for Older Women with Early-Stage Breast Cancer from 1983 to 1996. The Journals of Gerontology. Series A, Biological Sciences and Medical Sciences, 54, M474-M478. https://doi.org/10.1093/gerona/54.9.M474

[11] Hahn, C.A., et al. (2003) Breast Conservation Rates-Barriers between Tertiary Care and Community Practice. International Journal of Radiation Oncology, Biology, Physics, 55, 1196-1199. https://doi.org/10.1016/S0360-3016(02)04475-9

[12] Nattinger, A.B., et al. (2000) Relation between Appropriateness of Primary Therapy for Early-Stage Breast Carcinoma and Increased Use of Breast-Conserving Surgery. Lancet, 356, 1148-1153. https://doi.org/10.1016/S0140-6736(00)02757-4

[13] Morrow, M., et al. (2001) Factors Predicting the Use of Breast-Conserving Therapy in Stage I and II Breast Carcinoma. Journal of Clinical Oncology, 19, 2254-2262. https://doi.org/10.1200/JCO.2001.19.8.2254

[14] Clarke, M., et al. (2005) Effects of Radiotherapy and of Differences in the Extent of Surgery for Early Breast Cancer on Local Recurrence and 15-Year Survival: An Overview of the Randomised Trials. Lancet, 366, 2087-2106. https://doi.org/10.1016/S0140-6736(05)67887-7

[15] Kuske, R.R., et al. (2006) Phase II Trial of Brachytherapy alone after Lumpectomy for Select Breast Cancer: Toxicity Analysis of RTOG 95-17. International Journal of Radiation Oncology, Biology, Physics, 65, 45-51. https://doi.org/10.1016/j.ijrobp.2005.11.027

[16] King, T.A., et al. (2000) Long-Term Results of Wide-Field Brachytherapy as the Sole Method of Radiation Therapy after Segmental Mastectomy for T(is,1,2) Breast Cancer. The American Journal of Surgery, 180, 299-304. https://doi.org/10.1016/S0002-9610(00)00454-2

[17] Benitez, P.R., et al. (2007) Five-Year Results: The Initial Clinical Trial of MammoSite Balloon Brachytherapy for Partial Breast Irradiation in Early-Stage Breast Cancer. The American Journal of Surgery, 194, 456-462. https://doi.org/10.1016/j.amjsurg.2007.06.010

[18] Vicini, F., et al. (2008) Three-Year Analysis of Treatment Efficacy, Cosmesis, and Toxicity by the American Society of Breast Surgeons MammoSite Breast Brachytherapy Registry Trial in Patients Treated with Accelerated Partial Breast Irradiation (APBI). Cancer, 112, 758-766. https://doi.org/10.1002/cncr.23227 
[19] Patel, R.R., et al. (2008) Clinical Outcome Analysis in "High-Risk" versus "Low-Risk" Patients Eligible for National Surgical Adjuvant Breast and Bowel B-39/Radiation Therapy Oncology Group 0413 Trial: Five-Year Results. International Journal of Radiation Oncology, Biology, Physics, 70, 970-973. https://doi.org/10.1016/j.ijrobp.2007.12.005

[20] Ott, O.J., et al. (2007) Accelerated Partial Breast Irradiation with Multi-Catheter Brachytherapy: Local Control, Side Effects and Cosmetic Outcome for 274 Patients. Results of the German-Austrian Multi-Centre Trial. Radiotherapy \& Oncology, 82, 281-286. https://doi.org/10.1016/j.radonc.2006.08.028

[21] Kaufman, S.A., et al. (2007) Long-Term Outcome and Toxicity in a Phase I/II Trial Using High-Dose-Rate Multicatheter Interstitial Brachytherapy for T1/T2 Breast Cancer. Brachytherapy, 6, 286-292. https://doi.org/10.1016/j.brachy.2007.09.001

[22] Arthur, D.W., et al. (2008) A Phase II Trial of Brachytherapy alone after Lumpectomy for Select Breast Cancer: Tumor Control and Survival Outcomes of RTOG 95-17. International Journal of Radiation Oncology, Biology, Physics, 72, 467-473. https://doi.org/10.1016/j.ijrobp.2007.12.056

[23] Polgar, C., et al. (2007) Breast-Conserving Treatment with Partial or Whole Breast Irradiation for Low-Risk Invasive Breast Carcinoma-5-Year Results of a Randomized Trial. International Journal of Radiation Oncology, Biology, Physics, 69, 694-702. https://doi.org/10.1016/j.ijrobp.2007.04.022

[24] (2007) The American Society of Breast Surgeons-Performance and Practice Guidelines for Stereotactic Breast Procedures.

[25] Keisch, M., Arthur, D.W., Patel, R.R., et al. (2007) American Brachytherapy Society Breast Brachytherapy Task Group.

[26] Sauer, R., et al. (2007) Accelerated Partial Breast Irradiation: Consensus Statement of 3 German Oncology Societies. Cancer, 110, 1187-1194. https://doi.org/10.1002/cncr.22910

[27] (2007) Accelerated Partial Breast Irradiation as Sole Radiotherapy after Breast-Conserving Surgery for Early Stage Breast Cancer. Technology Evaluation Center Assessment Program. Executive Summary, 22, 1-4.

[28] Faverly, D., Holland, R. and Burgers, L. (1992) An Original Stereomicroscopic Analysis of the Mammary Glandular Tree. Virchows Archiv. A, Pathological Anatomy and Histopathology, 421, 115-119. https://doi.org/10.1007/BF01607043

[29] Faverly, D.R., et al. (1994) Three Dimensional Imaging of Mammary Ductal Carcinoma in Situ: Clinical Implications. Seminars in Diagnostic Pathology, 11, 193-198.

[30] Imamura, H., et al. (2000) Relationship between the Morphological and Biological Characteristics of Intraductal Components Accompanying Invasive Ductal Breast Carcinoma and Patient Age. Breast Cancer Research and Treatment, 62, 177-184. https://doi.org/10.1023/A:1006462328544

[31] Ohtake, T., et al. (1995) Intraductal Extension of Primary Invasive Breast Carcinoma Treated by Breast-Conservative Surgery. Computer Graphic Three-Dimensional Reconstruction of the Mammary Duct-Lobular Systems. Cancer, 76, 32-45. https://doi.org/10.1002/1097-0142(19950701)76:1\%3C32::AID-CNCR2820760106\% 3E3.0.CO;2-R

[32] Fisher, B. and Anderson, S. (1994) Conservative Surgery for the Management of Invasive and Noninvasive Carcinoma of the Breast: NSABP Trials. National Surgical Adjuvant Breast and Bowel Project. World Journal of Surgery, 18, 63-69. https://doi.org/10.1007/BF00348193 
[33] Fisher, E.R., et al. (1999) Pathologic Findings from the National Surgical Adjuvant Breast Project (NSABP) Eight-Year Update of Protocol B-17: Intraductal Carcinoma. Cancer, 86, 429-438.

https://doi.org/10.1002/(SICI)1097-0142(19990801)86:3\%3C429::AID-CNCR11\%3E 3.0.CO;2-Y

[34] Holli, K., et al. (2001) Lumpectomy with or without Postoperative Radiotherapy for Breast Cancer with Favourable Prognostic Features: Results of a Randomized Study. British Journal of Cancer, 84, 164-169. https://doi.org/10.1054/bjoc.2000.1571

[35] Uppsala-Orbero Breast Cancer Study Group. (1990) Sector Resection with or without Postoperative Radiotherapy for Stage I Breast Cancer: A Randomized Trial. Journal of the National Cancer Institute, 82, 277-282. https://doi.org/10.1093/jnci/82.4.277

[36] Clark, R.M., et al. (1996) Randomized Clinical Trial of Breast Irradiation Following Lumpectomy and Axillary Dissection for Node-Negative Breast Cancer: An Update. Ontario Clinical Oncology Group. Journal of the National Cancer Institute, 88, 1659-1664. https://doi.org/10.1093/jnci/88.22.1659

[37] Liljegren, G., et al. (1994) Sector Resection with or without Postoperative Radiotherapy for Stage I Breast Cancer: Five-Year Results of a Randomized Trial. Uppsala-Orebro Breast Cancer Study Group. Journal of the National Cancer Institute, 86, 717-722. https://doi.org/10.1093/jnci/86.9.717

[38] Morrow, M. (2002) Rational Local Therapy for Breast Cancer. The New England Journal of Medicine, 347, 1270-1271. https://doi.org/10.1056/NEJMe020112

[39] Kuske Jr., R.R. (1999) Breast Brachytherapy. Hematology/Oncology Clinics of North America, 13, 543-558. https://doi.org/10.1016/S0889-8588(05)70074-5

[40] Arthur, D.W., et al. (2003) Partial Breast Brachytherapy after Lumpectomy: Low-Dose-Rate and High-Dose-Rate Experience. International Journal of Radiation Oncology, Biology, Physics, 56, 681-689. https://doi.org/10.1016/S0360-3016(03)00120-2

[41] Hasan, Y., et al. (2008) Image Guidance in External Beam Accelerated Partial Breast Irradiation: Comparison of Surrogates for the Lumpectomy Cavity. International Journal of Radiation Oncology, Biology, Physics, 70, 619-625. https://doi.org/10.1016/j.ijrobp.2007.08.079

[42] Godinez, J., et al. (2008) Breast MRI in the Evaluation of Eligibility for Accelerated Partial Breast Irradiation. AJR, 191, 272-277. https://doi.org/10.2214/AJR.07.3465

[43] Cuttino, L.W., Todor, D. and Arthur, D.W. (2005) CT-Guided Multi-Catheter Insertion Technique for Partial Breast Brachytherapy: Reliable Target Coverage and Dose Homogeneity. Brachytherapy, 4, 10-17. https://doi.org/10.1016/j.brachy.2004.11.002

[44] Chen, P.Y., et al. (2006) Long-Term Cosmetic Results and Toxicity after Accelerated Partial-Breast Irradiation: A Method of Radiation Delivery by Interstitial Brachytherapy for the Treatment of Early-Stage Breast Carcinoma. Cancer, 106, 991-999. https://doi.org/10.1002/cncr.21681

[45] Edmundson, G.K., et al. (2002) Dosimetric Characteristics of the MammoSite RTS, a New Breast Brachytherapy Applicator. International Journal of Radiation Oncology, Biology, Physics, 52, 1132-1139. https://doi.org/10.1016/S0360-3016(01)02773-0

[46] Keisch, M., et al. (2003) Initial Clinical Experience with the MammoSite Breast Brachytherapy Applicator in Women with Early-Stage Breast Cancer Treated with 
Breast-Conserving Therapy. International Journal of Radiation Oncology, Biology, Physics, 55, 289-293. https://doi.org/10.1016/S0360-3016(02)04277-3

[47] Zannis, V., et al. (2005) Descriptions and Outcomes of Insertion Techniques of a Breast Brachytherapy Balloon Catheter in 1403 Patients Enrolled in the American Society of Breast Surgeons MammoSite Breast Brachytherapy Registry Trial. The American Journal of Surgery, 190, 530-538. https://doi.org/10.1016/j.amjsurg.2005.06.007

[48] Israel, P., Robbins, A.B., Shroff, P., et al. (2009) Initial Surgical Experience Evaluating Early Tolerance and Toxicities in Patients Undergoing Accelerated Partial Breast Irradiation Using the Contura Multi Lumen Balloon Breast Brachytherapy Catheter. The American Surgeon, 75, 1042-1049.

[49] Dickler, A., et al. (2009) A Dosimetric Comparison of MammoSite and ClearPath High-Dose-Rate Breast Brachytherapy Devices. Brachytherapy, 8, 14-18. https://doi.org/10.1016/j.brachy.2008.07.006

[50] Yashar, C.M., et al. (2009) Initial Clinical Experience with the Strut-Adjusted Volume Implant Brachytherapy Applicator for Accelerated Partial Breast Irradiation. Brachytherapy, 8, 367-372. https://doi.org/10.1016/j.brachy.2009.03.190

[51] Richardson, S.L. and Pino, R. (2010) Dosimetric Effects of an Air Cavity for the SAVI Partial Breast Irradiation Applicator. Medical Physics, 37, 3919-3926. https://doi.org/10.1118/1.3457328

[52] Weed, D.W., et al. (2005) Accelerated Partial Breast Irradiation: A Dosimetric Comparison of Three Different Techniques. Brachytherapy, 4, 121-129. https://doi.org/10.1016/j.brachy.2004.12.005

[53] Baglan, K.L., et al. (2003) Accelerated Partial Breast Irradiation Using 3D Conformal Radiation Therapy (3D-CRT). International Journal of Radiation Oncology, Biology, Physics, 55, 302-311. https://doi.org/10.1016/S0360-3016(02)03811-7

[54] Bovi, J., et al. (2007) Comparison of Three Accelerated Partial Breast Irradiation Techniques: Treatment Effectiveness Based upon Biological Models. Radiotherapy \& Oncology, 84, 226-232. https://doi.org/10.1016/j.radonc.2007.07.004

[55] Iaccarino, G., et al. (2007) Single Fraction Partial Breast Irradiation in Prone Position. Journal of Experimental \& Clinical Cancer Research, 26, 543-552.

[56] Kozak, K.R., et al. (2006) Accelerated Partial-Breast Irradiation Using Proton Beams: Initial Clinical Experience. International Journal of Radiation Oncology, Biology, Physics, 66, 691-698. https://doi.org/10.1016/j.ijrobp.2006.06.041

[57] Langen, K.M., et al. (2008) Investigation of Accelerated Partial Breast Patient Alignment and Treatment with Helical Tomotherapy Unit. International Journal of Radiation Oncology, Biology, Physics, 70, 1272-1280. https://doi.org/10.1016/j.ijrobp.2007.11.019

[58] Leonard, C.E., et al. (2011) Accelerated Partial Breast Intensity-Modulated Radiotherapy in Women Who Have Prior Breast Augmentation. Clinical Breast Cancer, 11, 184-190. https://doi.org/10.1016/j.clbc.2011.03.016

[59] Chen, P.Y., et al. (2010) Four-Year Efficacy, Cosmesis, and Toxicity Using Three-Dimensional Conformal External Beam Radiation Therapy to Deliver Accelerated Partial Breast Irradiation. International Journal of Radiation Oncology, Biology, Physics, 76, 991-997. https://doi.org/10.1016/j.ijrobp.2009.03.012

[60] Vicini, F., et al. (2010) Initial Efficacy Results of RTOG 0319: Three-Dimensional Conformal Radiation Therapy (3D-CRT) Confined to the Region of the Lumpectomy Cavity for Stage I/ II Breast Carcinoma. International Journal of Radiation 
Oncology, Biology, Physics, 77, 1120-1127.

https://doi.org/10.1016/j.ijrobp.2009.06.067

[61] Goyal, S., et al. (2013) Three-Year Outcomes of a Once Daily Fractionation Scheme for Accelerated Partial Breast Irradiation (APBI) Using 3-D Conformal Radiotherapy (3D-CRT). Cancer Medicine, 2, 964-971. https://doi.org/10.1002/cam4.157

[62] Reeder, R., et al. (2009) Predictors for Clinical Outcomes after Accelerated Partial Breast Intensity-Modulated Radiotherapy. International Journal of Radiation Oncology, Biology, Physics, 74, 92-97. https://doi.org/10.1016/j.ijrobp.2008.06.1917

[63] Jagsi, R., et al. (2010) Unacceptable Cosmesis in a Protocol Investigating Intensity-Modulated Radiotherapy with Active Breathing Control for Accelerated Partial-Breast Irradiation. International Journal of Radiation Oncology, Biology, Physics, 76, 71-78. https://doi.org/10.1016/j.ijrobp.2009.01.041

[64] Hepel, J.T., et al. (2009) Toxicity of Three-Dimensional Conformal Radiotherapy for Accelerated Partial Breast Irradiation. International Journal of Radiation Oncology, Biology, Physics, 75, 1290-1296. https://doi.org/10.1016/j.ijrobp.2009.01.009

[65] Lei, R.Y., et al. (2013) Four-Year Clinical Update from a Prospective Trial of Accelerated Partial Breast Intensity-Modulated Radiotherapy (APBIMRT). Breast Cancer Research and Treatment, 140, 119-133.

https://doi.org/10.1007/s10549-013-2623-x

[66] Beitsch, P.D., et al. (2010) Post-Surgical Treatment of Early-Stage Breast Cancer with Electronic Brachytherapy: An Intersociety, Multicenter Brachytherapy Trial. OncoTargets and Therapy, 3, 211-218. https://doi.org/10.2147/OTT.S14514

[67] Pignol, J.P., et al. (2009) Tolerance and Acceptance Results of a Palladium-103 Permanent Breast Seed Implant Phase I/II Study. International Journal of Radiation Oncology, Biology, Physics, 73, 1482-1488. https://doi.org/10.1016/j.ijrobp.2008.06.1945

[68] Afsharpour, H., et al. (2010) Influence of Breast Composition and Interseed Attenuation in Dose Calculations for Post-Implant Assessment of Permanent Breast 103Pd Seed Implant. Physics in Medicine \& Biology, 55, 4547-4561. https://doi.org/10.1088/0031-9155/55/16/S09

[69] Veronesi, U., et al. (2003) Full-Dose Intraoperative Radiotherapy with Electrons during Breast-Conserving Surgery. Archives of Surgery, 138, 1253-1256. https://doi.org/10.1001/archsurg.138.11.1253

[70] Veronesi, U., et al. (2001) A Preliminary Report of Intraoperative Radiotherapy (IORT) in Limited-Stage Breast Cancers That Are Conservatively Treated. European Journal of Cancer, 37, 2178-2183. https://doi.org/10.1016/S0959-8049(01)00285-4

[71] Kraus-Tiefenbacher, U., et al. (2005) Intraoperative Radiotherapy (IORT) for Breast Cancer Using the Intrabeam System. Tumori, 91, 339-345.

[72] Vaidya, J.S., et al. (2002) The Novel Technique of Delivering Targeted Intraoperative Radiotherapy (Targit) for Early Breast Cancer. European Journal of Surgical Oncology, 28, 447-454. https://doi.org/10.1053/ejso.2002.1275

[73] Vicini, F.A., et al. (2007) Long-Term Efficacy and Patterns of Failure after Accelerated Partial Breast Irradiation: A Molecular Assay-Based Clonality Evaluation. International Journal of Radiation Oncology, Biology, Physics, 68, 341-346. https://doi.org/10.1016/j.ijrobp.2006.12.007

[74] Vicini, F.A., et al. (2003) Limited-Field Radiation Therapy in the Management of Early-Stage Breast Cancer. Journal of the National Cancer Institute, 95, 1205-1210. 
https://doi.org/10.1093/jnci/djg023

[75] Goldstein, N.S., et al. (2005) Molecular Clonality Determination of Ipsilateral Recurrence of Invasive Breast Carcinomas after Breast-Conserving Therapy: Comparison with Clinical and Biologic Factors. American Journal of Clinical Pathology, 123, 679-689. https://doi.org/10.1309/DP47PK9PVC52AU4R

[76] Rodriguez, N., et al. (2013) Five-Year Outcomes, Cosmesis, and Toxicity with 3-Dimensional Conformal External Beam Radiation Therapy to Deliver Accelerated Partial Breast Irradiation. International Journal of Radiation Oncology, Biology, Physics, 87, 1051-1057. https://doi.org/10.1016/j.ijrobp.2013.08.046

[77] Polgar, C., et al. (2004) High-Dose-Rate Brachytherapy Alone versus Whole Breast Radiotherapy with or without Tumor Bed Boost after Breast-Conserving Surgery: Seven-Year Results of a Comparative Study. International Journal of Radiation Oncology, Biology, Physics, 60, 1173-1181. https://doi.org/10.1016/j.ijrobp.2004.05.012

[78] Polgar, C., et al. (2002) Sole Brachytherapy of the Tumor Bed after Conservative Surgery for T1 Breast Cancer: Five-Year Results of a Phase I-II Study and Initial Findings of a Randomized Phase III Trial. Journal of Surgical Oncology, 80, 121-129. https://doi.org/10.1002/jso.10110

[79] Strnad, V., Ott, O.J., Hildebrandt, G., Kauer-Dorner, D., Knauerhase, H., Major, T., et al. (2016) 5-Year Results of Accelerated Partial Breast Irradiation Using Sole Interstitial Multicatheter Brachytherapy versus Whole-Breast Irradiation with Boost After Breast-Conserving Surgery for Low-Risk Invasive and In-Situ Carcinoma of the Female Breast: A Randomised, Phase 3, Non-Inferiority Trial. The Lancet, 387, 229-238. https://doi.org/10.1016/S0140-6736(15)00471-7

[80] Shaitelman, S.F., Amendola, B., Khan, A., Beriwal, S., Rabinovitch, R., Demanes, D.J. and Cuttino, L. (2016) American Brachytherapy Society Task Group Report: Long-Term Control and Toxicity with Brachytherapy for Localized Breast Cancer. Brachytherapy.

[81] Yashar, C., Attai, D., Butler, E., Einck, J., Finkelstein, S., Han, B., et al. (2016) Strut-Based Accelerated Partial Breast Irradiation: Report of Treatment Results for 250 Consecutive Patients at 5 Years from a Multicenter Retrospective Study. Brachytherapy, 15, 780-787. https://doi.org/10.1016/j.brachy.2016.07.002

[82] Lawenda, B.D., et al. (2003) Dose-Volume Analysis of Radiotherapy for T1N0 Invasive Breast Cancer Treated by Local Excision and Partial Breast Irradiation by Low-Dose-Rate Interstitial Implant. International Journal of Radiation Oncology, Biology, Physics, 56, 671-680. https://doi.org/10.1016/S0360-3016(03)00071-3

[83] Vicini, F.A., et al. (2005) First Analysis of Patient Demographics, Technical Reproducibility, Cosmesis, and Early Toxicity: Results of the American Society of Breast Surgeons MammoSite Breast Brachytherapy Trial. Cancer, 104, 1138-1148. https://doi.org/10.1002/cncr.21289

[84] Cuttino, L.W., et al. (2008) Multi-Institutional Experience Using the MammoSite Radiation Therapy System in the Treatment of Early-Stage Breast Cancer: 2-Year Results. International Journal of Radiation Oncology, Biology, Physics, 71, 107-114. https://doi.org/10.1016/j.ijrobp.2007.09.046

[85] Beitsch, P.D., Zannis, V., et al. (2008) Recurrence and Survival in the American Society of Breast Surgeons (ASBS) MammoSite RTS Registry Trial. International Journal of Radiation Oncology, Biology, Physics, 72, S2-S3. https://doi.org/10.1016/j.ijrobp.2008.06.773

[86] Belkacemi, Y., et al. (2009) Partial Breast Irradiation as Sole Therapy for Low Risk Breast Carcinoma: Early Toxicity, Cosmesis and Quality of Life Results of a Mam- 
moSite Brachytherapy Phase II Study. Radiotherapy \& Oncology, 90, 23-29. https://doi.org/10.1016/j.radonc.2008.06.004

[87] Chao, K.K., et al. (2007) Analysis of Treatment Efficacy, Cosmesis, and Toxicity Using the MammoSite Breast Brachytherapy Catheter to Deliver Accelerated Partial-Breast Irradiation: The William Beaumont Hospital Experience. International Journal of Radiation Oncology, Biology, Physics, 69, 32-40. https://doi.org/10.1016/j.ijrobp.2007.02.026

[88] Shah, C., et al. (2013) Treatment Efficacy with Accelerated Partial Breast Irradiation (APBI): Final Analysis of the American Society of Breast Surgeons MammoSite((R)) Breast Brachytherapy Registry Trial. Annals of Surgical Oncology, 20, 3279-3285. https://doi.org/10.1245/s10434-013-3158-4

[89] Formenti, S.C., et al. (2002) T1 Stage Breast Cancer: Adjuvant Hypofractionated Conformal Radiation Therapy to Tumor Bed in Selected Postmenopausal Breast Cancer Patients-Pilot Feasibility Study. Radiology, 222, 171-178.

https://doi.org/10.1148/radiol.2221010769

[90] Remouchamps, V.M., et al. (2003) Three-Dimensional Evaluation of Intra- and Interfraction Immobilization of Lung and Chest wall Using Active Breathing Control: A Reproducibility Study with Breast Cancer Patients. International Journal of Radiation Oncology, Biology, Physics, 57, 968-978. https://doi.org/10.1016/S0360-3016(03)00710-7

[91] Rusthoven, K.E., et al. (2008) Accelerated Partial-Breast Intensity-Modulated Radiotherapy Results in Improved Dose Distribution When Compared with Three-Dimensional Treatment-Planning Techniques. International Journal of Radiation Oncology, Biology, Physics, 70, 296-302. https://doi.org/10.1016/j.ijrobp.2007.08.047

[92] White, E.A., et al. (2007) Cone Beam Computed Tomography Guidance for Setup of Patients Receiving Accelerated Partial Breast Irradiation. International Journal of Radiation Oncology, Biology, Physics, 68, 547-554. https://doi.org/10.1016/j.ijrobp.2007.01.048

[93] Patel, R.R., et al. (2007) A Dosimetric Comparison of Accelerated Partial Breast Irradiation Techniques: Multicatheter Interstitial Brachytherapy, Three-Dimensional Conformal Radiotherapy, and Supine Versus Prone Helical Tomotherapy. International Journal of Radiation Oncology, Biology, Physics, 68, 935-942. https://doi.org/10.1016/j.ijrobp.2007.03.005

[94] Whelan, T.J., et al. (2010) Long-Term Results of Hypofractionated Radiation Therapy for Breast Cancer. The New England Journal of Medicine, 362, 513-520. https://doi.org/10.1056/NEJMoa0906260

[95] Taghian, A.G., et al. (2006) Initial Dosimetric Experience Using Simple Three-Dimensional Conformal External-Beam Accelerated Partial-Breast Irradiation. International Journal of Radiation Oncology, Biology, Physics, 64, 1092-1099. https://doi.org/10.1016/j.ijrobp.2005.09.042

[96] Vicini, F.A., et al. (2007) Interim Cosmetic Results and Toxicity Using 3d Conformal External Beam Radiotherapy to Deliver Accelerated Partial Breast Irradiation in Patients with Early-Stage Breast Cancer Treated with Breast-Conserving Therapy. International Journal of Radiation Oncology, Biology, Physics, 69, 1124-1130. https://doi.org/10.1016/j.ijrobp.2007.04.033

[97] Zelefsky, M.J., et al. (2008) Incidence of Late Rectal and Urinary Toxicities after Three-Dimensional Conformal Radiotherapy and Intensity-Modulated Radiotherapy for Localized Prostate Cancer. International Journal of Radiation Oncology, 
Biology, Physics, 70, 1124-1129. https://doi.org/10.1016/j.ijrobp.2007.11.044

[98] Sheets, N.C., et al. (2012) Intensity-Modulated Radiation Therapy, Proton Therapy, or Conformal Radiation Therapy and Morbidity and Disease Control in Localized Prostate Cancer. JAMA, 307, 1611-1120. https://doi.org/10.1001/jama.2012.460

[99] Pignol, J.P., et al. (2008) A Multicenter Randomized Trial of Breast Intensity-Modulated Radiation Therapy to Reduce Acute Radiation Dermatitis. Journal of Clinical Oncology, 26, 2085-2092. https://doi.org/10.1200/JCO.2007.15.2488

[100] Barnett, G.C., et al. (2009) A Randomised Controlled Trial of Forward-Planned Radiotherapy (IMRT) for Early Breast Cancer: Baseline Characteristics and Dosimetry Results. Radiotherapy \& Oncology, 92, 34-41. https://doi.org/10.1016/j.radonc.2009.03.003

[101] Harsolia, A., et al. (2007) Intensity-Modulated Radiotherapy Results in Significant Decrease in Clinical Toxicities Compared with Conventional Wedge-Based Breast Radiotherapy. International Journal of Radiation Oncology, Biology, Physics, 68, 1375-1380. https://doi.org/10.1016/j.ijrobp.2007.02.044

[102] Sharma, N.K., et al. (2011) Intensity-Modulated Radiotherapy Reduces Gastrointestinal Toxicity in Patients Treated with Androgen Deprivation Therapy for Prostate Cancer. International Journal of Radiation Oncology, Biology, Physics, 80, 437-444. https://doi.org/10.1016/j.ijrobp.2010.02.040

[103] Bergom, C., et al. (2013) A Phase I/II Study Piloting Accelerated Partial Breast Irradiation Using CT-Guided Intensity Modulated Radiation Therapy in the Prone Position. Radiotherapy \& Oncology, 108, 215-219. https://doi.org/10.1016/j.radonc.2013.05.039

[104] Polgár, C., Fodor, J., Major, T., Sulyok, Z. and Kásler, M. (2013) Breast-Conserving Therapy with Partial or Whole Breast Irradiation: Ten-Year Results of the Budapest Randomized Trial. Radiotherapy \& Oncology, 108, 197-202. https://doi.org/10.1016/j.radonc.2013.05.008

[105] Livi, L., Meattini, I., Marrazzo, L., Simontacchi, G., Pallotta, S., Saieva, C., et al. (2015) Accelerated Partial Breast Irradiation Using Intensity-Modulated Radiotherapy versus Whole Breast Irradiation: 5-Year Survival Analysis of a Phase 3 Randomised Controlled Trial. European Journal of Cancer, 51, 451-463. https://doi.org/10.1016/j.ejca.2014.12.013

[106] Coles, C., Agrawal, R., Ah-See, M.L., et al. (2016) Partial Breast Radiotherapy for Women with Early Breast Cancer: First Results of Local Recurrence Data for IMPORT-LOW (CRUK/06/003). European Journal of Cancer, 57, S4.

[107] Vicini, F.A., et al. (2003) Ongoing Clinical Experience Utilizing 3D Conformal External Beam Radiotherapy to Deliver Partial-Breast Irradiation in Patients with Early-Stage Breast Cancer Treated with Breast-Conserving Therapy. International Journal of Radiation Oncology, Biology, Physics, 57, 1247-1253. https://doi.org/10.1016/S0360-3016(03)01573-6

[108] Pashtan, I.M., et al. (2012) External Beam Accelerated Partial-Breast Irradiation Using 32 gy in 8 Twice-Daily Fractions: 5-Year Results of a Prospective Study. International Journal of Radiation Oncology, Biology, Physics, 84, e271-e277. https://doi.org/10.1016/j.ijrobp.2012.04.019

[109] Vaidya, J.S., et al. (2005) TARGeted Intraoperative Radiotherapy (TARGIT): An Innovative Approach to Partial-Breast Irradiation. Seminars in Radiation Oncology, 15, 84-91. https://doi.org/10.1016/j.semradonc.2004.10.007

[110] Veronesi, U., et al. (2008) Full-Dose Intra-Operative Radiotherapy with Electrons 
(ELIOT) during Breast-Conserving Surgery: Experience with 1246 Cases. Ecancermedicalscience, 2,65 .

[111] Vaidya, J.S., et al. (2001) Targeted Intra-Operative Radiotherapy (Targit): An Innovative Method of Treatment for Early Breast Cancer. Annals of Oncology, 12, 1075-1080. https://doi.org/10.1023/A:1011609401132

[112] Vaidya, J.S., et al. (2014) Risk-Adapted Targeted Intraoperative Radiotherapy versus Whole-Breast Radiotherapy for Breast Cancer: 5-Year Results for Local Control and Overall Survival from the TARGIT-A Randomised Trial. Lancet, 383, 603-613. https://doi.org/10.1016/S0140-6736(13)61950-9

[113] Holmes, D.R., Baum, M. and Joseph, D. (2007) The TARGIT Trial: Targeted Intraoperative Radiation Therapy versus Conventional Postoperative Whole-Breast Radiotherapy after Breast-Conserving Surgery for the Management of Early-Stage Invasive Breast Cancer (a Trial Update). The American Journal of Surgery, 194, 507-510. https://doi.org/10.1016/j.amjsurg.2007.06.018

[114] Beal, K., et al. (2007) Single-Fraction Intraoperative Radiotherapy for Breast Cancer: Early Cosmetic Results. International Journal of Radiation Oncology, Biology, Physics, 69, 19-24. https://doi.org/10.1016/j.ijrobp.2007.02.010

[115] Stitzenberg, K.B., et al. (2007) In Vivo Intraoperative Radiotherapy: A Novel Approach to Radiotherapy for Early Stage Breast Cancer. Annals of Surgical Oncology, 14, 1515-1516. https://doi.org/10.1245/s10434-006-9152-3

[116] Osti, M.F., et al. (2013) Exclusive Electron Intraoperative Radiotherapy in Early Stage Breast Cancer: A Monoinstitutional Experience. Anticancer Research, 33, 1229-1235.

[117] Lee, K.S., et al. (2014) Metastatic Potential in MDA-MB-231 Human Breast Cancer Cells Is Inhibited by Proton Beam Irradiation via the Akt/nucLear Factor-KappaB Signaling Pathway. Molecular Medicine Reports, 10, 1007-1012. https://doi.org/10.3892/mmr.2014.2259

[118] Kanai, T., et al. (1980) Spot Scanning System for Proton Radiotherapy. Medical Physics, 7, 365-369. https://doi.org/10.1118/1.594693

[119] Wang, X., et al. (2013) Accelerated Partial-Breast Irradiation Using Intensity-Modulated Proton Radiotherapy: Do Uncertainties Outweigh Potential Benefits? The British Journal of Radiology, 86, Article ID: 20130176. https://doi.org/10.1259/bjr.20130176

[120] Welsh, J., et al. (2011) Intensity-Modulated Proton Therapy Further Reduces Normal Tissue Exposure during Definitive Therapy for Locally Advanced Distal Esophageal Tumors: A Dosimetric Study. International Journal of Radiation Oncology, Biology, Physics, 81, 1336-1342. https://doi.org/10.1016/j.ijrobp.2010.07.2001

[121] Taghian, A.G., et al. (2006) Accelerated Partial Breast Irradiation Using Proton Beams: Initial Dosimetric Experience. International Journal of Radiation Oncology, Biology, Physics, 65, 1404-1410. https://doi.org/10.1016/j.ijrobp.2006.03.017

[122] Kozak, K.R., et al. (2006) Dosimetric Comparison of Proton and Photon Three-Dimensional, Conformal, External Beam Accelerated Partial Breast Irradiation Techniques. International Journal of Radiation Oncology, Biology, Physics, 65, 1572-1578. https://doi.org/10.1016/j.ijrobp.2006.04.025

[123] Galland-Girodet, S., et al. (2014) Long-Term Cosmetic Outcomes and Toxicities of Proton Beam Therapy Compared with Photon-Based 3-Dimensional Conformal Accelerated Partial-Breast Irradiation: A Phase 1 Trial. International Journal of Radiation Oncology, Biology, Physics, 90, 493-500.

https://doi.org/10.1016/j.ijrobp.2014.04.008 
[124] Njeh, C.F., Saunders, M.W. and Langton, C.M. (2012) Accelerated Partial Breast Irradiation Using External Beam Conformal Radiation Therapy: A Review. Critical Reviews in Oncology/ Hematology, 81, 1-20. https://doi.org/10.1016/j.critrevonc.2011.01.011

[125] Pignol, J.P., et al. (2006) First Report of a Permanent Breast 103Pd Seed Implant as Adjuvant Radiation Treatment for Early-Stage Breast Cancer. International Journal of Radiation Oncology, Biology, Physics, 64, 176-181. https://doi.org/10.1016/j.ijrobp.2005.06.031

[126] Keller, B.M., et al. (2012) Permanent Breast Seed Implant Dosimetry Quality Assurance. International Journal of Radiation Oncology, Biology, Physics, 83, 84-92. https://doi.org/10.1016/j.ijrobp.2011.05.030

[127] Orton, C.G. and Webber, B.M. (1977) Time-Dose Factor (TDF) Analysis of Dose rate Effects in Permanent Implant Dosimetry. International Journal of Radiation Oncology, Biology, Physics, 2, 55-60. https://doi.org/10.1016/0360-3016(77)90008-6

[128] Fentiman, I.S., et al. (1996) Inadequacy of Iridium Implant as Sole Radiation Treatment for Operable Breast Cancer. European Journal of Cancer, 32A, 608-611. https://doi.org/10.1016/0959-8049(95)00639-7

[129] Magee, B., et al. (1996) Prognostic Factors for Breast Recurrence after Conservative Breast Surgery and Radiotherapy: Results from a Randomised Trial. Radiotherapy \& Oncology, 39, 223-227. https://doi.org/10.1016/0167-8140(96)01747-1

[130] Perera, F., et al. (2003) Patterns of Breast Recurrence in a Pilot Study of Brachytherapy Confined to the Lumpectomy Site for Early Breast Cancer with Six Years' Minimum Follow-Up. International Journal of Radiation Oncology, Biology, Physics, 57, 1239-1246. https://doi.org/10.1016/S0360-3016(03)00816-2

[131] Shah, C., Vicini, F., Wazer, D.E., et al. (2013) The American Brachytherapy Society Consensus Statement for Accelerated Partial Breast Irradiation. Brachytherapy, 12, 267-277.

https://www.americanbrachytherapy.org/guidelines/Guidelines_Accelerated_Partial Breast_Irradiation.pdf

[132] (2011) The American Society of Breast Surgeons-Consensus Statement for Accelerated Partial Breast Irradiation.

https://www.breastsurgeons.org/new_layout/about/statements/PDF_Statements/AP BI.pdf

[133] Smith, B.D., et al. (2009) Accelerated Partial Breast Irradiation Consensus Statement from the American Society for Radiation Oncology (ASTRO). Journal of the American College of Surgeons, 209, 269-277. https://doi.org/10.1016/j.jamcollsurg.2009.02.066

[134] Manyam, B.V., Tendulkar, R., Cherian, S., Vicini, F., Badiyan, S.N. and Shah, C. (2016) Evaluating Candidacy for Hypofractionated Radiation Therapy, Accelerated Partial Breast Irradiation, and Endocrine Therapy after Breast Conserving Surgery. American Journal of Clinical Oncology. Cancer Clinical Trials. https://doi.org/10.1097/COC.0000000000000332

[135] Greene, F.L., Page, D., Fleming, I., et al. (2002) The American Joint Committee on Cancer: Updating the Strategies in Cancer Staging. Bulletin of the American College of Surgeons, 87, 13-15.

[136] Sher, D.J., et al. (2009) Partial-Breast Irradiation versus Whole-Breast Irradiation for Early-Stage Breast Cancer: A Cost-Effectiveness Analysis. International Journal of Radiation Oncology, Biology, Physics, 74, 440-446.

https://doi.org/10.1016/j.ijrobp.2008.08.015 